\title{
Exon repression by polypyrimidine tract binding protein
}

\author{
BATOUL AMIR-AHMADY, ${ }^{1}$ PAUL L. BOUTZ, ${ }^{1}$ VADIM MARKOVTSOV,${ }^{1,4}$ MARTIN L. PHILLIPS, ${ }^{2}$ and \\ DOUGLAS L. BLACK ${ }^{1,3}$ \\ ${ }^{1}$ Department of Microbiology, Immunology \& Molecular Genetics, ${ }^{2}$ Department of Chemistry and Biochemistry, and ${ }^{3}$ Howard Hughes \\ Medical Institute, University of California, Los Angeles, California 90095-1662, USA
}

\begin{abstract}
Polypyrimidine tract binding protein (PTB) is known to silence the splicing of many alternative exons. However, exons repressed by PTB are affected by other RNA regulatory elements and proteins. This makes it difficult to dissect the structure of the pre-mRNP complexes that silence splicing, and to understand the role of PTB in this process. We determined the minimal requirements for PTB-mediated splicing repression. We find that the minimal sequence for high affinity binding by PTB is relatively large, containing multiple polypyrimidine elements. Analytical ultracentrifugation and proteolysis mapping of RNA cross-links on the PTB protein indicate that most PTB exists as a monomer, and that a polypyrimidine element extends across multiple PTB domains. The high affinity site is bound initially by a PTB monomer and at higher concentrations by additional PTB molecules. Significantly, this site is not sufficient for splicing repression when placed in the $3^{\prime}$ splice site of a strong test exon. Efficient repression requires a second binding site within the exon itself or downstream from it. This second site enhances formation of a multimeric PTB complex, even if it does not bind well to PTB on its own. These experiments show that PTB can be sufficient to repress splicing of an otherwise constitutive exon, without binding sites for additional regulatory proteins and without competing with U2AF binding. The minimal complex mediating splicing repression by PTB requires two binding sites bound by an oligomeric PTB complex.
\end{abstract}

Keywords: alternative splicing; splicing regulation; RNP complex; protein-RNA interactions

\section{INTRODUCTION}

Polypyrimidine tract binding protein (PTB) is an abundant, widely expressed, nuclear RNA binding protein. PTB has been implicated in a variety of cellular processes affecting gene expression, most notably alternative splicing (Valcarcel and Gebauer 1997; Smith and Valcarcel 2000; Wagner and Garcia-Blanco 2001; Black 2003). In systems of alternative splicing, PTB often serves as a repressor of highly tissuespecific exons outside of a particular cell type, such as muscle cells or neurons (Wagner and Garcia-Blanco 2001; Black and Grabowski 2003). Many mammalian alternative exons are known to be affected by the action of PTB, including exons in actinin (Southby et al. 1999; Gromak et al.

${ }^{4}$ Present address: Rigel, Inc., 1180 Veterans Blvd., South San Francisco, CA 94080, USA.

Reprint requests to: Douglas L. Black, Department of Microbiology, Immunology \& Molecular Genetics, University of California Los Angeles, Los Angeles, CA 90095-1662, USA; e-mail: dougb@microbio.ucla.edu.

Article and publication are at http://www.rnajournal.org/cgi/doi/ 10.1261/rna.2250405.
2003), tropomyosin (Mulligan et al. 1992; Gooding et al. 1994, 1998; Pérez et al. 1997a), troponin (Charlet et al. 2002), c-src (Chan and Black 1997; Chou et al. 2000), fibronectin (Norton 1994; Flanagan et al. 2003), FGF receptors 1 and 2 (Carstens et al. 2000; Jin et al. 2003), and IgM (Shen et al. 2004). In all of these transcripts, PTB binds to short pyrimidine-rich elements within the RNA encompassing the regulated exon. These elements are usually multiple, but are distributed through the exon region differently in each transcript.

PTB (also called hnRNP I) is a $58-\mathrm{kDa}$ protein, containing four RNA binding domains of the RRM type (also called an RNP-cs domain or an RBD) (Varani and Nagai 1998), an $\mathrm{N}$-terminal domain involved in nuclear localization and export, and a hinge region between RRMs 2 and 3, whose length varies due to alternative splicing of the PTB transcript itself (Valcarcel and Gebauer 1997; Wagner and Garcia-Blanco 2001). PTB binds to short RNA elements containing mixtures of $\mathrm{C}$ and $\mathrm{U}$, such as UUCU or UCUCU (Singh et al. 1995; Pérez et al. 1997b; Simpson et al. 2004). These can be adjacent to non-pyrimidine-rich RNA, but for high affinity binding are often found within a pyrimidine- 
rich context. PTB binding sites are commonly found within the polypyrimidine tract of the $3^{\prime}$ splice site of the regulated exon. Studies of individual domains of the protein indicate that all the RRMs can bind to RNA. RRM 2 may also be involved in protein dimerization (Pérez et al. 1997b; Oh et al. 1998; Simpson et al. 2004). Several studies indicate that RNA binding activity is not sufficient for splicing repression. When one of the PTB binding sites within the FGF R2 transcript was replaced with the MS2 RNA binding site, a MS2/PTB fusion protein could repress splicing, whereas the MS2 protein alone could not (Wagner and Garcia-Blanco 2002). Repression activity is affected by the splicing alterations in the central non-RRM region of the protein (Wollerton et al. 2001). Finally, an analysis of mutant proteins in an in vitro splicing system uncovered a special role of RRM 4 in splicing repression; small C-terminal deletions within this domain produce a protein that still binds RNA but has lost its splicing repression activity (Liu et al. 2002). Solution structures of the independent RRMs have been solved by NMR (Conte et al. 2000; Simpson et al. 2004), and some contacts of these domains with short RNA oligonucleotides have been identified (Yuan et al. 2002; Simpson et al. 2004). The interpretation of all these results is limited because high affinity binding and splicing repression both require fulllength protein. Thus, an understanding of the mechanism of splicing repression will require a picture of the multiple combined contacts of full-length PTB with an extended RNA.

Systems of alternative splicing are generally highly combinatorial (Smith and Valcarcel 2000; Black 2003). Alternative exons are affected by multiple RNA elements and RNA binding proteins. These elements are both positive and negative acting and are often combined to create an intricate regulatory region of RNA that allows cooperative assembly of multiple RNA binding proteins into large RNP complexes. This makes it difficult to assess the roles of individual proteins such as PTB in these complexes and to do experiments directed at elucidating their mechanisms of action.

The N1 exon of the $c$-src gene is an example of a mammalian exon that is controlled by a number of different inputs (Black 2003). This exon is spliced in neurons and skipped in nonneuronal cells. The splicing of the exon requires an intronic splicing enhancer downstream of the exon (Modafferi and Black 1997; Black 2003). This enhancer is relatively non-tissue specific and to prevent N1 splicing in nonneuronal cells, the exon is repressed by PTB protein (Chan and Black 1995; Chou et al. 2000). Splicing repression requires elements that bind PTB both upstream and downstream from the N1 exon (Chan and Black 1995, 1997; Chou et al. 2000). The upstream sites bind PTB with high affinity but downstream elements are within the enhancer region and bind PTB relatively weakly. To allow stable binding to these sites, PTB cooperatively assembles with other proteins binding to adjacent elements, including
hnRNP's H and F and KSRP (Chou et al. 1999; Markovtsov et al. 2000). These other proteins could be involved splicing repression and derepression or take part in the enhancer function. In some cells, where PTB is present but the N1 exon is spliced, PTB appears to be counteracted by a neuronal homolog of PTB, called $\mathrm{nPTB}$ or brPTB (Markovtsov et al. 2000; Polydorides et al. 2000). This protein binds to the repressor elements in place of PTB but does not repress splicing. Although PTB is required for N1 splicing repression, it is difficult to assess its mechanism of action in the face of the other proteins needed for its efficient assembly.

In this study, we examine the mechanism of PTB-mediated splicing repression and the nature of its interaction with pre-mRNA. We assessed the stoichiometry of PTB binding and the structure of the multimeric PTB complex that leads to splicing repression. We determined the minimal sequence necessary for high affinity RNA binding and then asked how many of these elements are sufficient to repress an exon that is normally constitutive. We find that PTB alone can repress splicing in the absence of other regulatory elements. Moreover, we show that splicing repression requires multiple binding sites but does not require competition for U2AF binding to the $3^{\prime}$ splice site.

\section{RESULTS}

\section{Delineation of a minimal PTB binding site}

We first set out to determine the minimal sequence necessary for high affinity binding of PTB. The known PTB binding site upstream from the $\mathrm{N} 1$ exon encompasses $36 \mathrm{nt}$ between the branch point and the AG dinucleotide and contains two copies of the element CUUCUCUCU as well as other runs of pyrimidines (Fig. 1A,B). The affinity of this sequence (Probe A) for PTB was measured by gel shift assay. Increasing amounts of recombinant PTB-1 were incubated with Probe $A$ and these mixtures were separated by native gel (Fig. 1B). A protein/RNA complex forms at relatively low protein concentrations, exhibiting an apparent $K_{d}$ of 50 $\mathrm{nM}$. At much higher concentrations of protein $(0.5-1 \mu \mathrm{M})$, Complex 1 is shifted into the more slowly migrating Complex 2. This complex evidently contains a higher stoichiometry of PTB, but this second binding step is of much lower affinity than the first. The apparent $K_{d}$ of the PTB interaction was also measured by filter binding assay. This binding data also best fit a two-binding-site curve, but yielded higher affinities with $K_{d}$ of $1 \mathrm{nM}$ and $143 \mathrm{nM}$ for the two binding steps (data not shown). Similar results were also seen with the PTB-4 isoform (data not shown). A similar binding constant was also obtained with a mixture of PTB-1 and PTB-4 purified from HeLa extract, although in some preparations the HeLa protein showed a somewhat higher affinity than recombinant PTB (data not shown).

The 38-nt length of Probe A is longer than would be 
Downloaded from rnajournal.cshlp.org on April 25, 2023 - Published by Cold Spring Harbor Laboratory Press

A

\begin{tabular}{|c|c|}
\hline A $38 \mathrm{nt}$ & AGC CUC UCC UUC UCU CUG CUU CUC UCU CGC UGG CCC UU \\
\hline B $40 \mathrm{nt}$ & GG AGC CUC UCC UUC UCU CUG CUU CUC UCU CGC UGG CCC UU \\
\hline C $40 \mathrm{nt}$ & GG AGC CUC UCA ACA AAA ACG CUU CUC UCU CGC UGG CCC UU \\
\hline D $40 \mathrm{nt}$ & GG AGC CUC UCA ACA AAA ACG AAC AAA AAC CGC UGG CCC UU \\
\hline E $40 \mathrm{nt}$ & GG AGA ACA ACC UUC UCU CUG CUU CUC UCU CGC UGG CCC UU \\
\hline $\mathrm{F} 40 \mathrm{nt}$ & GG AGC CUC UCC UUC UCU CUG CUU CUC UCU CGC UGG UGG UU \\
\hline G $40 \mathrm{nt}$ & GG AGA ACA ACC UUC UCU CUG CUU CUC UCU CGC UGG UGG UU \\
\hline
\end{tabular}

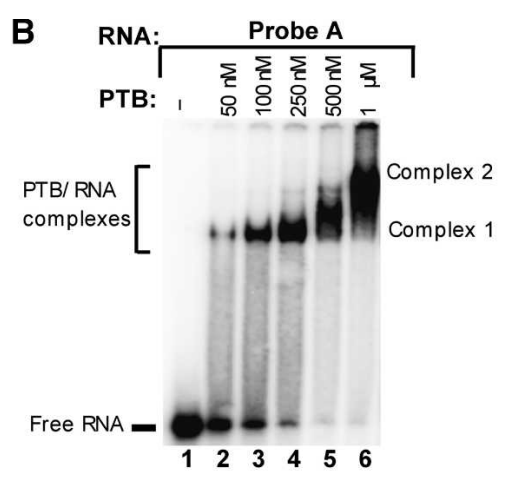

N1

C 5. *GG CAC CUC AGC CUC UCC UUC UCU CUG CUU CUC UCU CGC UGg CCC UUA GGA GGA AGG UGC CAU CGA UGU CAG ${ }^{*}$ pC 3 , Complex 2
Complex 1

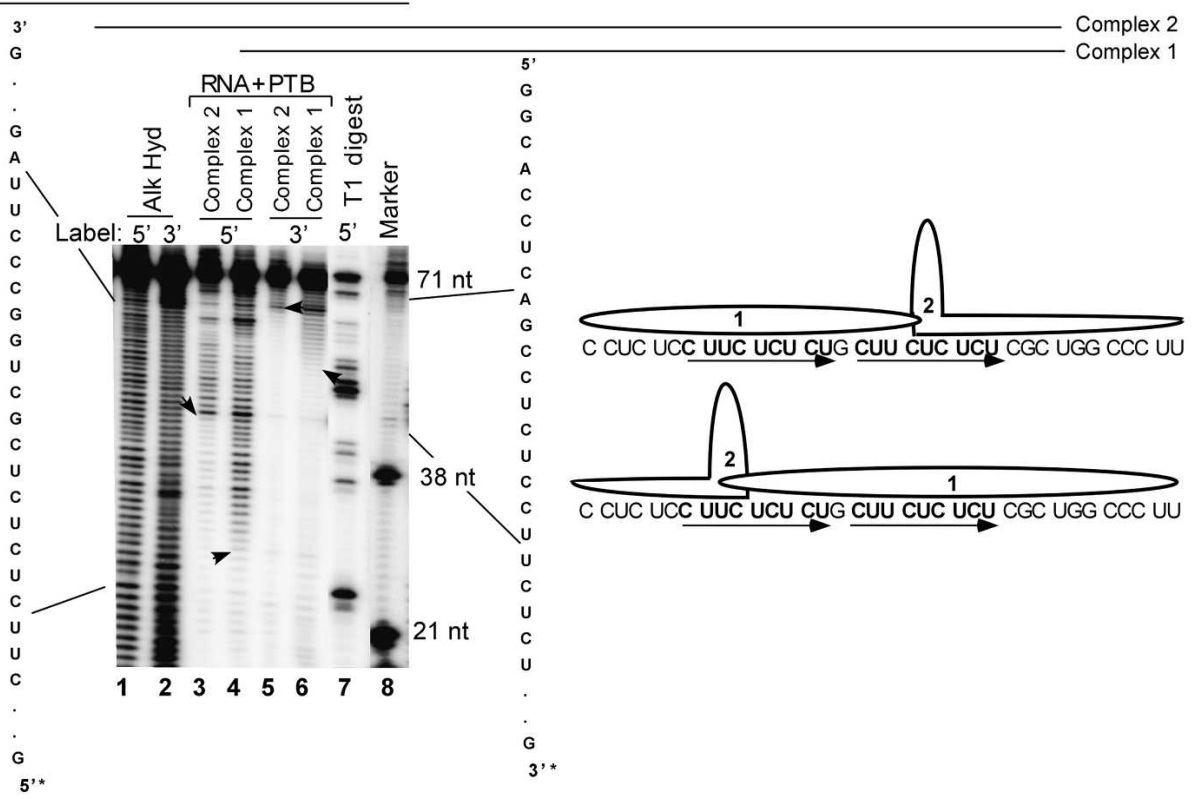

D

E

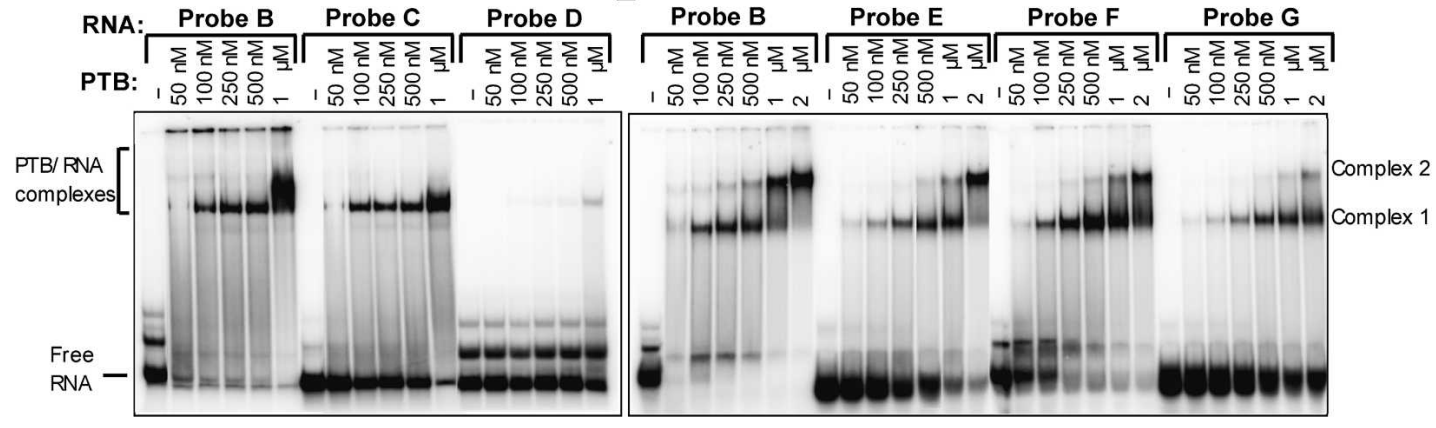

FIGURE 1. Characterization of a minimal RNA binding site for PTB. (A) Diagrams of the RNA probes derived from N1 $3^{\prime}$ splice site that were used in an electrophoretic mobility shift assay (EMSA). (B) EMSA of recombinant PTB binding to a 38-nt c-src N1 exon 3' splice site (Probe A). (Lane 1) free RNA (50,000 cpm $\sim 10 \mathrm{fmol}$ ). (Lanes 2-6) RNA incubated with increasing amounts of PTB in the amounts shown. The PTB/RNA Complexes 1 and 2 are indicated. (C) Boundary determination of Complexes 1 and 2. An RNA probe comprising the c-src N1 exon and part of the upstream intron was labeled at its $3^{\prime}$ or $5^{\prime}$ end, subjected to partial alkaline hydrolysis (lanes 1,2), and incubated with PTB. The PTB/RNA complexes were separated on a native gel as in $B$, and the RNA was eluted and analyzed on the denaturing gel shown. The $3^{\prime}$ boundaries of the $5^{\prime}$-end-labeled RNA (lanes 3,4) and 5' boundaries of the $3^{\prime}$-end-labeled RNA (lanes 5,6) for the interaction with PTB are indicated by arrows. A partial RNAse T1 digestion of the $5^{\prime}$ end-labeled RNA (lane 7) and small RNA size markers (lane 8) allowed identification of the fragments in each ladder. The fragments are aligned with the sequence at the top. A diagram of the two possible protein interactions for each complex is shown to the right. (D) EMSA of PTB binding to the wild-type 3' splice site (Probe B) and to this sequence with one (Probe C) or both (Probe D) CUUCUCUCU elements mutated. Note that Complex 2 forms only on Probe B. (E) EMSA of PTB binding to the wild-type N1 3' splice site (Probe B) and to probes with the upstream (Probe E) or downstream (Probe F) pyrimidine elements mutated or both (Probe G). Note that loss of the two pyrimidine elements nearly eliminates Complex 2 formation. 
expected to be bound by a single PTB protein, even one with four RNA binding domains (Varani and Nagai 1998). To determine the extent of RNA bound in each complex, we performed boundary analyses to identify the length of RNA needed to assemble into each complex (Jellinek et al. 1994; Bevilacqua et al. 1998; Darnell et al. 2001). A longer RNA encompassing the nucleotides of Probe A was labeled at either its $5^{\prime}$ or $3^{\prime}$ end, subjected to partial alkaline hydrolysis, and bound to PTB. RNA was isolated from either Complex 1 or Complex 2 on the native gel and separated on a denaturing gel (Fig. 1C). This results in a ladder of bands from the hydrolytic fragments of RNA. The shortest RNA found in a particular complex corresponds to the length of RNA needed to form that complex, from the label to the hydrolyzed end. As expected, Complex 1 can form on a shorter RNA than Complex 2. With the RNA labeled at the 5 ' end, this complex can form on a 30-nt RNA, extending through the branch point, the first CUUCUCUCU repeat, and the first $4 \mathrm{nt}$ of the second repeat. Complex 2 requires a longer RNA, extending $46 \mathrm{nt}$ through the second CUU CUCUCU repeat and into a polypyrimidine element just upstream of the splice site AG. Using a $3^{\prime}$ labeled RNA, Complex 1 assembles on RNAs that begin within the first repeat and run through the second repeat to the $3^{\prime}$ end of the RNA. Complex 2 binds mRNA that encompasses this downstream sequence, but extends upstream through all of the first CUUCUCUCU element and additional upstream pyrimidines (Fig. 1C, top).

These boundary analysis experiments are consistent with the model that in forming Complex 1, PTB is binding in either of two positions. In each position, the binding site includes all of one of the two CUUCUCUCU elements and extends to 4-6 additional pyrimidine nucleotides on either side of this element. This creates a mixture of two complexes. As the concentration of protein is increased and Complex 2 is formed, additional nucleotides are occupied. On this short probe there is apparently little cooperativity in the binding of the second protein, which requires fairly high protein concentrations. Given the size of the first binding site and the relative affinity of the second binding step, the interaction of the second protein is not equivalent to the first.

To examine these interactions more carefully, we measured binding of the protein to shorter or mutated RNA probes. A shorter 17-nt probe, containing a single CUU CUCUCU repeat plus additional pyrimidines upstream, does not form Complex 1 and only forms observable complexes at high protein concentrations (data not shown). The loss of affinity and unusual gel mobility seen with the shorter probes indicated that both repeats were needed for the formation of the high affinity Complex 1 . This spurred us to examine RNAs of equivalent length to the $3^{\prime}$ splice site probe, but carrying mutations in groups of pyrimidines. Probe B is equivalent to Probe A, but is $2 \mathrm{nt}$ longer (40 nt) due to the addition of guanosines at the 5 ' end derived from the T7 promoter (Fig. 1A). This RNA shows the same PTB binding properties as Probe A (Fig. 1D), generating both Complex 1 and Complex 2. Probe $\mathrm{C}$ is the same as Probe $\mathrm{B}$ but with the upstream pyrimidine repeat element mutated. This probe shows somewhat lower affinity for the protein and forms only Complex 1. When both of the upstream and downstream pyrimidine repeats are mutated (Probe D), the RNA loses nearly all PTB binding. Thus Complex 1 formation requires the presence of at least one repeat and Complex 2 requires both. Maintaining the two repeat elements but eliminating the pyrimidines either upstream or downstream from them had little effect on Complex 1 formation (Fig. 1E, Probes E and F). However, mutating both of these flanking pyrimidine elements greatly reduced Complex 2 formation (Probe G). Complex 1 still formed on Probe G but at lower affinity. Thus, at least one repeat is needed for Complex 1 formation, while Complex 2 requires both repeats plus an adjacent pyrimidine element, either upstream or downstream. These results agree well with the positions of the boundaries for Complexes 1 and 2 seen in Figure 1C.

\section{The stoichiometry and interactions of PTB in RNA/protein complexes}

An important question in understanding the assembly of PTB into these complexes is the stoichiometry of binding. It was reported that PTB in solution migrates in a gel filtration column with an apparent molecular mass of $\sim 120 \mathrm{kDa}$, approximately equivalent to a dimer of $58-\mathrm{kDa}$ monomers (Pérez et al. 1997b). We have repeated these experiments with similar results (data not shown). However, besides dimerization, such mobility could also be explained by a nonspherical shape for the protein. Similarly, yeast two hybrid and protein-protein cross-linking studies indicated that PTB could interact with itself (Oh et al. 1998). However, this cross-linking was inefficient, perhaps indicating that only a small percent of the protein was in a multimeric form. To clarify whether the majority of PTB in solution is a dimer or a monomer, we determined the apparent molecular mass of PTB-1 in solution by analytical ultracentrifugation (Laue 2001). Using buffer conditions similar to our binding reactions, equilibrium sedimentation analysis of PTB yielded a molecular weight of 61,100 Da, very close to the 57,523 Da of a PTB-1 monomer (Fig. 2A). Sedimentation velocity experiments were also performed to obtain a sedimentation coefficient (S) value for the PTB. The observed $S$ value for PTB shows a tight distribution centered at $3.3 \mathrm{~S}\left(\mathrm{~S}_{20, \mathrm{w}}=3.4 \mathrm{~S}\right)$, again indicating that the protein is primarily monomeric in solution (Fig. 2B). However, a spherical protein of the molecular weight of PTB should have a sedimentation coefficient of $\sim 4.1 \mathrm{~S}$. The lower observed $S$ value for PTB indicates an asymmetric structure (the frictional ratio, f/fo, calculated from the data is 1.6) as might be expected for the four RRM domains. Thus Complex 1, which forms on the binding site at low concentra- 
A

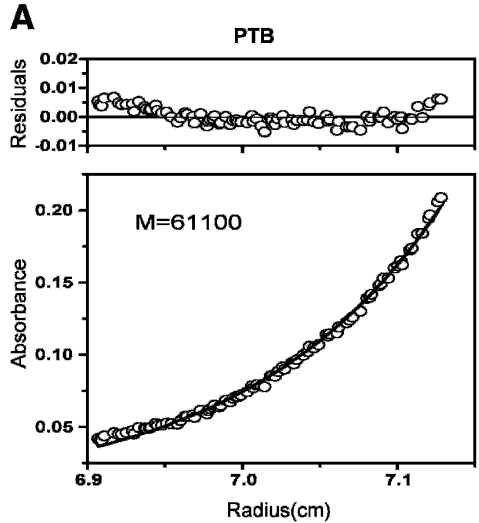

B

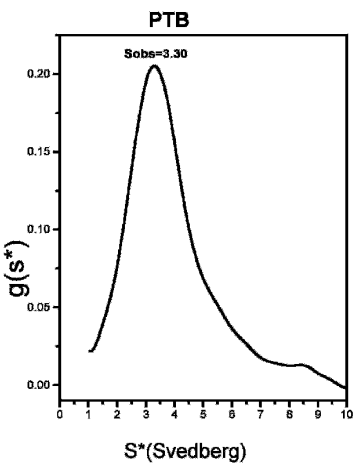

FIGURE 2. PTB is monomeric in solution. (A) The equilibrium absorbance gradient of PTB at $20^{\circ} \mathrm{C}$ and $12,000 \mathrm{rpm}$ is shown as circles along with a nonlinear least-squares single exponential fit to the data. The average molecular weight from the fit was $61 \mathrm{kDa}$, and the upper panel shows the deviations of the data from the fit. $(B)$ The sedimentation coefficient distribution (uncorrected for diffusion) of PTB determined from sedimentation velocity at $55,000 \mathrm{rpm}$ and $20^{\circ} \mathrm{C}$. The $\mathrm{g}$ (s) parameter indicates the fraction of material with the sedimentation coefficient $S$.

tions of protein, most likely contains a single PTB monomer. Complex 2 would then represent the addition of at least one additional monomer to fully occupy the site.

The binding and centrifugation data suggest that Complex 1 contains a single PTB monomer occupying $\sim 20 \mathrm{nt}$ of RNA. This amount of sequence should be engaged by multiple RRM domains. To examine the interactions of different portions of the protein with the RNA, we cross-linked RNA to the protein and mapped these cross-links to the peptide sequence by proteolysis (Fig. 3). In initial characterizations, we cross-linked recombinant PTB to a long RNA by shortwave UV. The protein was then subjected to progressive cleavage over time with GluC protease (Fig. 3B, Coomassie panel, and $3 \mathrm{~A}$ ). The fragments within this digestion pattern that correspond to $\mathrm{N}$ or C-terminal fragments were identified on immunoblots probed with antibodies to either the N- or C-terminal peptide of PTB (Fig. $3 \mathrm{~B}$, Western panels). The $\mathrm{N}$ terminus is very sensitive to proteolysis and is removed very early in the digestion (lanes 16-19). In contrast, the C-terminal fragments exhibit a progressive shortening over time producing a ladder of bands by $90 \mathrm{~min}$ (lanes 11-14). When a N1 exon splicing substrate labeled with ${ }^{32} \mathrm{P}-\mathrm{UTP}$ was incubated with recombinant PTB, irradiated with shortwave UV, and subjected to RNAse treatment, the protein was efficiently labeled by a cross-linked RNA oligonucleotide. When this labeled protein was subjected to partial GluC proteolysis, the pattern of labeled bands closely resembled the pattern of C-terminal fragments identified in the immunoblots (Fig. 3B, crosslink panels; cf. lanes 7-9 and lanes 11-14). At 90 min of protease treatment, the labeled RNA cross-link resided predominantly in a C-terminal fragment of $\sim 28 \mathrm{kDa}$ (lane 9).
This places the cross-link (or cross-links) within either RRM 3 or RRM 4 (Fig. 3B).

Partial and complete cyanogen bromide cleavage of the protein further delineated the cross-link position to a 102 residue fragment extending from the $\mathrm{C}$ terminus of RRM 3 to the middle of RRM 4 (Fig. 3A, Fig. 3C, middle lane, and data not shown; see also Fig. 3E). The protein was then subjected to exhaustive cleavage with the proteases GluC, LysC, AspN, and trypsin, and to pairs of these enzymes (data not shown). All of these enzymes generated a single predominant labeled fragment, indicating that there was one predominant site of cross-linking. The sizes of the peptide products from these different limit digests place this cross-linking site within the peptide NFQNIFPPSATLHL SNIPPSVSE. This encompasses the RNP2 motif within beta strand 1 of RRM 4, and also includes residues from the linker between RRMs 3 and 4. Given its role in RNA recognition in other proteins, the RNP2 motif is a very likely position for direct interaction with the RNA. There is a histidine in this sequence with potential to cross-link to RNA under shortwave UV. However, there are also aromatic residues within the linker whose role in the cross-link cannot be ruled out (Meisenheimer and Koch 1997).

Because shortwave UV cross-linking is very dependent on the nature of the protein residues interacting with the RNA, the single cross-link generated by this method cannot be taken as evidence that other parts of the protein are not in direct contact with RNA. Such contacts may not cross-link efficiently by this method. To look more generally for RNA contacts on the protein, we employed cross-linking to RNAs substituted with 4-thiouridine. This modified nucleotide is activated to cross-link in long wavelength UV (366 nm). These cross-links require close juxtaposition of the substituted base with the reactive protein, but can occur at many different groups on the protein (Meisenheimer and Koch 1997). The N1 exon 3' splice site was substituted with 4-thioU, labeled with ${ }^{32} \mathrm{P}$, and cross-linked to PTB. The protein was then subjected to complete cyanogen bromide cleavage and the fragments resolved by SDS-PAGE (Fig. 3C, right lane). This treatment produces the same major 102 residue $\mathrm{CNBr}$ fragment seen with shortwave cross-linking, derived from portions of RRMs 3 and 4 (asterisk $\sim 12.5$ $\mathrm{kDa}$ ). However, the 4-thioU cross-linking produces two additional fragments, which can also be seen as minor species in the shortwave cross-linking. One of these fragments is $\sim 6.5 \mathrm{kDa}$ in size. There are only two peptides of this size in PTB that can be produced by $\mathrm{CNBr}$ cleavage and both are derived from RRM 1. The other CNBr peptide is $\sim 3.4 \mathrm{kDa}$. This could derive from either the extreme $\mathrm{N}$ terminus or the extreme $\mathrm{C}$ terminus of the protein.

In the initial 4-thioU cross-linking experiments, all of the uridine residues in the N1 $3^{\prime}$ splice site were substituted with the analog. If multiple RRMs of a PTB monomer were interacting with one of the pyrimidine repeats in the $3^{\prime}$ splice site, then different positions along one repeat should 
A PTB $50 \quad 100 \quad 150 \quad 200 \quad 250 \quad 300 \quad 350 \quad 400 \quad 450 \quad 500$

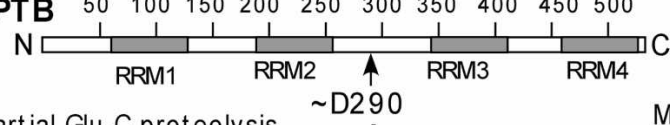

B partial Glu-C proteolysis partial and exhaustive

$\mathrm{CNBr}$ cleavage

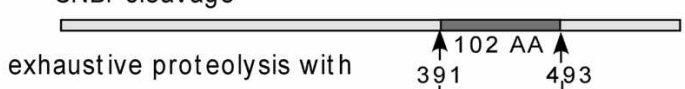
Minuteso $m$ 으 잉요

\section{Coomassie Crosslink C-Term western} 의용 요유용

$\mathrm{N}$-Term western
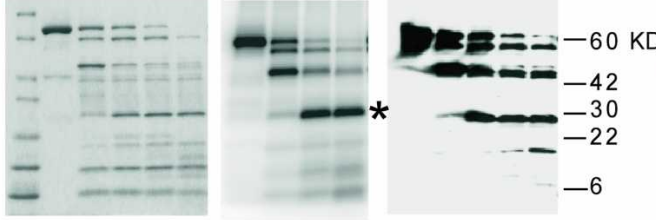

$\begin{array}{llllllllllllll}1 & 2 & 3 & 4 & 5 & 6 & 7 & 8 & 9 & 10 & 11 & 12 & 13 & 14\end{array}$
으으요요

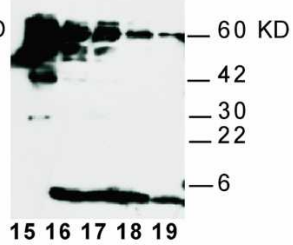

Trypsin, GluC, AspN and LysC

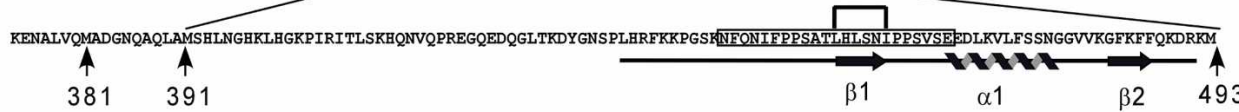

C

Probe:cỬcứcưcùcG

Probe:cucucu N1-3'sS N1-3'sS

Crosslinking:254nm $254 \mathrm{~nm}$ sU $366 \mathrm{~nm}$
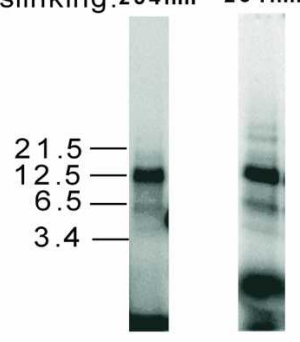

Site Labeled:

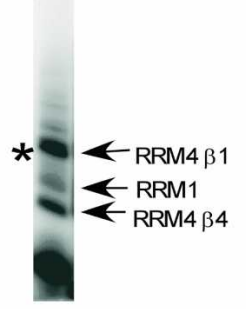

Site Labeled: 23579

Crosslinked PTB - -

CNBr Cleaved Protein

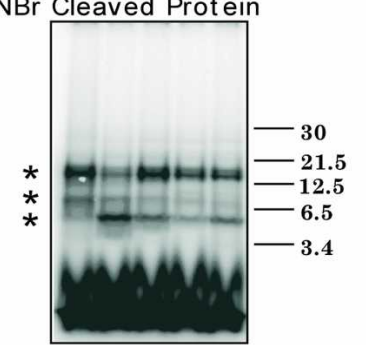

23579
Sit e Labeled: 2
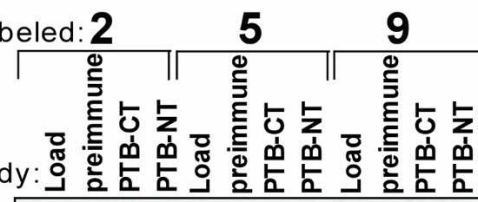

E

1 MDGIVPDIAV GTKRGSDELF STCVTNGPFI MSSNSASAAN GNDSKKFKGD SRSAGVPSRV IHIRKLPIDV TEGEVISLGL

81 PFGKVTNLLIM LKGKNQAFIE MNTEEAANTIM VNYYTSVTPV LRGQPIYIQF SNHKELKTDS SPNQARAQAA LQAVNSVQSG 161 NLALAASAAA VDAGMAMAGQ SPVLRIIVEN LFYPVTLDVL HQIFSKFGTV LKIITFTKNN QFQALLQYAD PVSAQHAKLS

241 LDGQNIYNAC CTLRIDFSKL TSLNVKYNND KSRDYTRPDL PSGDSQPSLD QTMAAAFGLS VPNVHGALAP LAIPSAAAAA 321 AAAGRIAIPG LAGAGNSVLL VSNLNPERVT PQSLFILFGV YGDVQRVKIL FNKKENALVQ MADGNQAQLA MSHLNGHKLH 401 GKPIRITLSK HQNVQLPREG QEDQGLTKDY GNSPLHRFKK PGSKNFQNIF PPSATLHLSN IPPSVSEEDL KVLFSSNGGV 481 VKGFKFFQKD RKIMALIQMGS VEEAVQALID LHNHDLGENH HLRVSFSKST I

Met Fragment size: $\quad 30 \quad 59 \quad 11 \quad 9 \quad 65 \quad 2 \quad \begin{array}{lllllll} & 31 & 88 & 10 & 102 & 5 & 33\end{array}$

Cleavage site: $\quad 1,31,90,101,110,175,177,293,381,391,493,498$

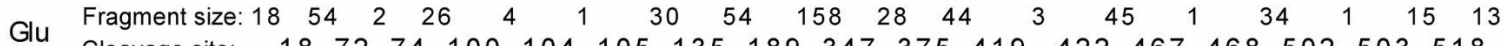

Cleavage site: $\quad 18,72,74,100,104,105,135,189,347,375,419,422,467,468,502,503,518$

Asp Cleavage site: $\quad 2,7,17,43,50,69,139,172,198,230,242,256,270,274,279,284,290,363,383$

$423,429,489,490,510,515$

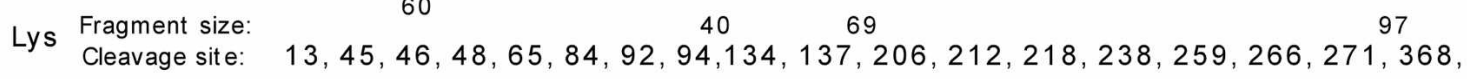
$373,374,398,402,410,428,439,440,444,471,482,485,489,492,528$

FIGURE 3. (Legend on next page) 
be interacting with different peptides within the protein. To examine this, we made a series of CUUCUCUCUCG RNA oligonucleotides, each containing one 4-thioU in place of a uridine residue (Fig. 3D, top left). Each oligo was 5 '-end labeled, incubated with PTB protein, and cross-linked. Cross-linking was performed in a large excess of PTB to ensure that each protein bound no more than one RNA. Each oligo cross-linked with similar efficiency to the protein, creating a labeled protein with the full oligo attached (Fig. 3D, top left panel). When these proteins were subjected to $\mathrm{CNBr}$ cleavage, the same labeled fragments were observed as with the fully substituted probe (Fig. 3D, bottom left panel). The sizes of these fragments were somewhat larger because the RNA was not cleaved prior to $\mathrm{CNBr}$ treatment and electrophoresis. Interestingly, the distribution of these fragments varied with the position of the 4-thiouridine. All of the substitutions cross-linked to the large peptide are seen with shortwave UV cross-linking. However, the amount of this fragment varied. The crosslinking of the other two peptides was even more dependent on the labeling site. A repeat RNA carrying 4-thioU at position 2 showed significantly more cross-linking to the peptide derived from RRM 1 than did the other probes. In contrast, the RNA carrying 4-thioU at position 3 was primarily cross-linked to the smaller peptide. This peptide could derive from one of the two termini. To identify this fragment, the cross-linked peptides were subjected to immunoprecipitation with antibodies reactive with each terminus (Fig. 3D, right panel). Antibody to the $\mathrm{C}$ terminus brought down the fragment, whereas the N-terminal antibodies did not. Thus, this fragment corresponds to the extreme $\mathrm{C}$ terminus of RRM 4. Substitutions at positions 5, 7, and 9 cross-linked primarily to peptide 1 . Note that this peptide is long and the position of cross-linking for each substitution may differ. The variation in cross-linked peptides across the repeat indicate that each position of the repeat is interacting with a different portion of the protein. Although we cannot rule out interactions with RRMs 2 and
3, a single repeat is apparently interacting with both RRMs 1 and 4 .

\section{PTB-mediated exon silencing in vivo requires multiple protein binding sites in the target RNA}

The binding experiments indicate that PTB can form different kinds of complexes on a pyrimidine-rich RNA. To determine the minimal PTB complex that can repress splicing, we constructed a series of splicing reporters carrying different types and combinations of PTB binding sites (Fig. $4 \mathrm{~A})$. The minigene pDUP175 contains a 175-nt hybrid exon derived from fusing the $5^{\prime}$ end of $\beta$-globin exon 2 to the $3^{\prime}$ end of $\beta$-globin exon 1 (Dominski and Kole 1991; Modafferi and Black 1997). This test exon is flanked by wild-type $\beta$-globin exons 1 and 2 and nearly identical introns. The construct is driven by the CMV promoter, and shows nearly constitutive test exon inclusion when expressed in a wide variety of cells (Fig. 4B, lane 1; data not shown). To test whether a single high affinity PTB site was sufficient to mediate splicing repression, the $\beta$-globin $3^{\prime}$ splice site of this test exon was replaced with the complete $\mathrm{N} 1$ exon $3^{\prime}$ splice site, including the branch point and the polypyrimidine tract that exhibits high affinity PTB binding. This site only showed weak silencing activity, as exon skipping increased to only $\sim 10 \%$ (DS1; Fig. 4B, lane 2, Fig. 4C). Placement of the complete polypyrimidine tract (without the branch point or AG) into the test exon itself also results in only modest repression of splicing (DS2; Fig. 4B, lane 3). Although either of these two introduced PTB sites have weak effects on their own, when two sites are present in the same RNA, the splicing is strongly repressed (57\% exon exclusion, DS3; Fig. 4B, lane 4, Fig. 4C). Thus, significant splicing repression is not observed unless two binding sites are present in the transcript. The downstream binding site does not need to be in the exon itself. In the DS4 construct, the element was placed in the intron $16 \mathrm{nt}$ downstream of the test exon $5^{\prime}$ splice site. Again this ele-

FIGURE 3. Mapping positions of RNA contact on the PTB protein. (A) Flow chart for mapping the PTB/BS7 RNA cross-link. Partial Glu-C proteolysis maps the cross-link to a position C-terminal of D290. Partial and exhaustive $\mathrm{CNBr}$ cleavage $(C)$ maps the cross-link to a 102-residue peptide between M 391 and M 493. Complete digestion with pairs of proteases further delineates the cross-link to the peptide NFQNIFPPSATLHLSNIPPSVSE, encompassing $\beta$ strand 1 of RRM 4. (B) Partial Glu-C proteolysis of PTB cross-linked to $\alpha-{ }^{32}$ PUTP-labeled BS7 RNA. After $254 \mathrm{~nm}$ UV cross-linking and RNAse A + T1 treatment, PTB was subject to Glu-C digestion. Equivalent digestion reactions were visualized by Coomassie staining (left panel), autoradiography (second panel from the left), and Western blot using antibodies against the $\mathrm{C}$ terminus (second panel from the right) or the $\mathrm{N}$ terminus (right panel) of PTB. The asterisk indicates the primary labeled (28 $\mathrm{kDa}$ ) cleavage product from Glu-C digestion. $(C)$ Comparison of the $\mathrm{CNBr}$ fragments of PTB after cross-linking to different RNA templates and by different methods. (Left lane) PTB cross-linked to a $5^{\prime}$ end-labeled CUCUCU oligo at $254 \mathrm{~nm}$. (Middle lane) PTB cross-linked to uniformly $\alpha-{ }^{32}$ PUTPlabeled N1-3' splice site RNA at $254 \mathrm{~nm}$. (Right lane) PTB cross-linked to 4-thio UTP substituted 3' splice site RNA at $366 \mathrm{~nm}$ UV. Both of the N1-3' SS RNA samples were treated with RNAse prior to the CNBr digestion. The asterisk indicates the major cross-linking product seen with all methods. (D) PTB cross-linking to a single CUUCUCUCUCG repeat RNA containing single 4-thioU substitutions. (Top left) The efficiency of PTB cross-linking to the CUUCUCUCUCG oligo at $366 \mathrm{~nm}$ is similar regardless of the position of the 4-thioU substitution. (Bottom left) Exhaustive CNBr cleavage of the cross-linked proteins shown above. Asterisks indicate the major cross-linked products. Note that these CNBr fragments exhibit slower gel mobility than those in $C$ because they were not digested with RNAse prior to separation. (Right panel) Immunoprecipitation of the PTB CNBr fragments using $\mathrm{N}$ - or C-terminal antibodies. The 4-thioU substitution site is indicated at the top. $\mathrm{CNBr}$ cleaved protein from each reaction (Load) was subjected to immunoprecipitation with preimmune serum or with antibody raised to the N- or C-terminal 15-residue peptide of PTB. Note that only the smallest peptide is bound by the C-terminal antibody. (E) Proteolysis sites in PTB. Residues subject to specific cleavage are shown in color. Predicted products are shown below. 
ment had little effect on its own, but was strongly inhibitory when present with the $3^{\prime}$ splice site element (DS5; Fig. 4B, lane 6; Fig. 4C).

In DS6, the pyrimidines upstream of the repeated element were deleted (Fig. 4A). This mutation reduces binding somewhat (Fig. 1E) and also reduces splicing repression slightly (Fig. 4B, lane 7). The src N1 exon has an unusual branch point that does not match the consensus well. When this is changed to the better $\beta$-globin branch point, the repression by PTB is lost (DS7; Fig. 4B, lane 8). Thus, even when two binding sites are present, the ability of PTB to repress splicing is affected by how well the constitutive splicing elements are recognized by the general splicing apparatus.

The presence of the PTB binding site within the polypyrimidine tract of the $3^{\prime}$ splice site presumably means that PTB binding is in competition with U2AF 65 (Lin and Patton 1995; Singh et al. 1995). This makes the analysis of mutations within the sequence difficult because base changes could affect the binding of either protein. To examine whether the PTB binding site must be within the $3^{\prime}$ splice site for repression to occur, we moved the element upstream from the branch point. This construct (DS8, Fig. $4 \mathrm{~A})$ retains the $\beta$-globin branch point and polypyrimidine tract in the $3^{\prime}$ splice site of the test exon, but now has a high affinity PTB binding site upstream of these elements. As before, this site had little effect on splicing when present alone, but was strongly inhibitory when another binding site was present within the exon (DS9; Fig. 4B, lane 10, Fig. 4C). Thus, direct competition with U2AF binding is not a requirement for PTBmediated splicing repression. This separation of the PTB binding site from the U2AF site allows the analysis of pyrimidine mutations. Deletion of the pyrimidines either upstream or downstream of the repeated elements drastically reduced splicing repression (DS10, DS11; Fig. 4B, lanes 11,12). Deletion of both of these sequences had a still stronger effect (DS12; Fig. 4B, lane 13). The reduced splicing repression seen with these sequences parallels the observed PTB binding of these elements (Fig. 1). The loss of repression is particularly strong when both elements are mutated, creat- ing a sequence that cannot form the higher order Complex 2.

The requirement for a weak branch point in PTB-mediated splicing regulation implied that the level of repression would vary depending on the basal inclusion of the exon. To examine this, we made some of the same constructs in the DUP-51 backbone. These constructs contain the same exons as DUP-175 except that the hybrid middle exon is now $51 \mathrm{nt}$ and this short exon is excluded from the mRNA
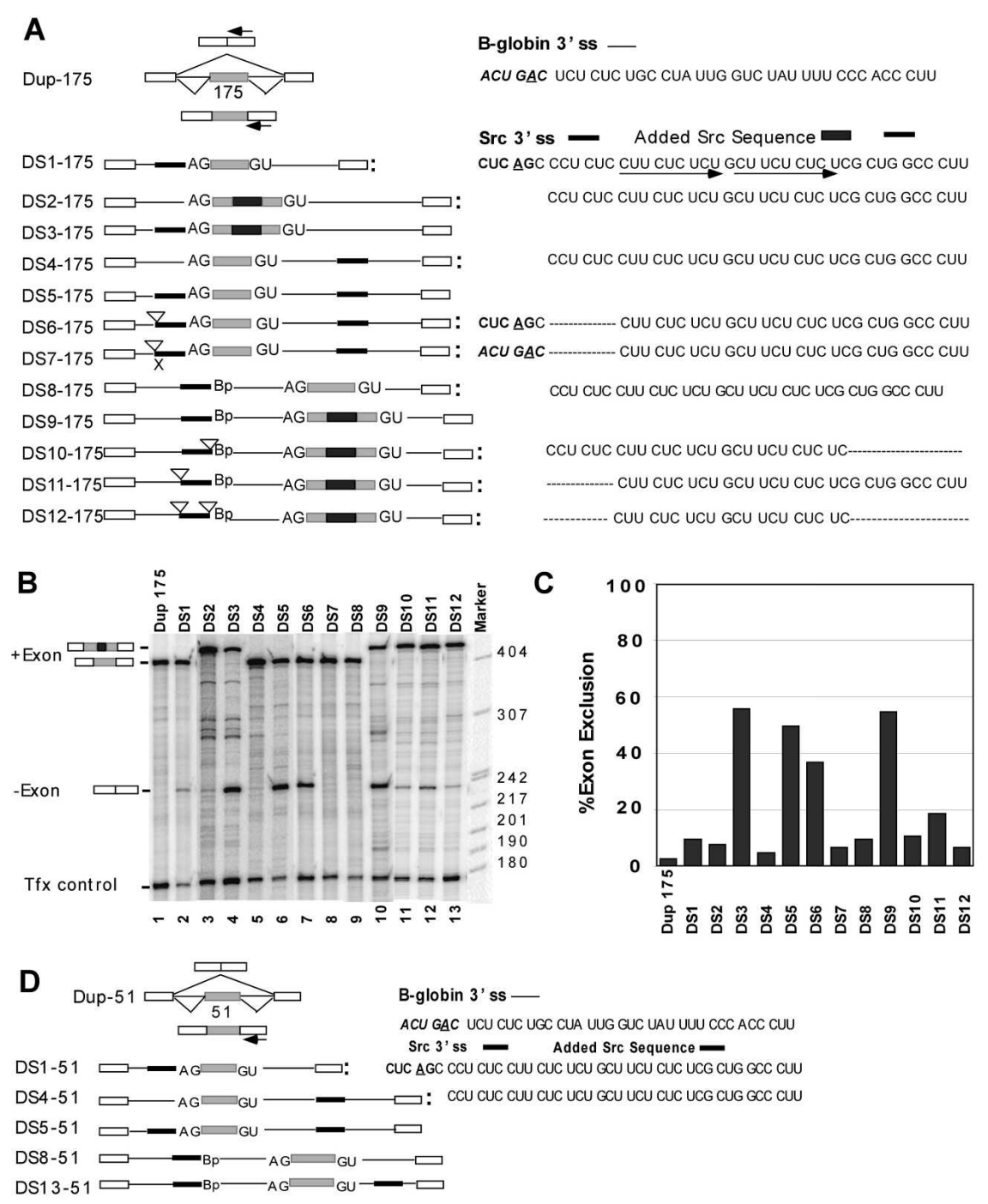

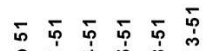

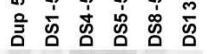

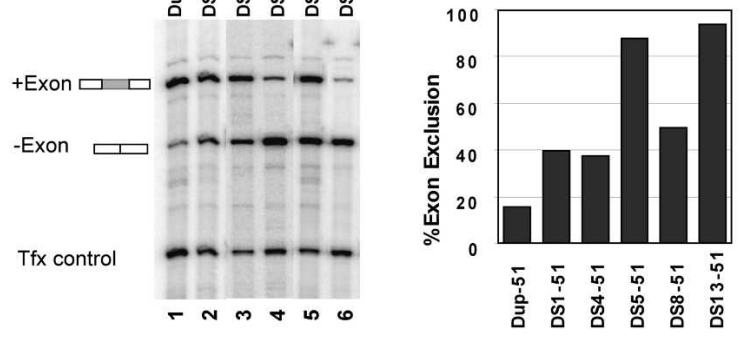

FIGURE 4. (Legend on next page) 
at higher frequency ( $18 \%$ exon exclusion; Fig. $4 \mathrm{D}$, lane 1$)$. In this reporter, the PTB binding sites did indeed have stronger effects. Single high affinity binding sites placed in the $3^{\prime}$ splice site or in the downstream intron both approximately double the level of exon exclusion (Fig. $4 \mathrm{D}$, lanes 2,3). A site placed upstream of the branch point also had a stronger effect (Fig. 4D, lane 5). Again, combining two of these sites strongly potentiated the splicing repression, raising the level of exon exclusion to $\sim 90 \%$ (Fig. 4D, lanes 4,6).

To confirm that the splicing repression observed in the DS minigenes was indeed mediated by PTB, we knocked down expression of PTB in the transfected cells by RNA interference and analyzed the splicing of the minigene transcripts. These experiments were carried out in HeLa cells rather than HEK293, because we have obtained more efficient RNAi-mediated knockdown in these cells. The cells were first treated with siRNA, incubated for $48 \mathrm{~h}$ to induce PTB knockdown, and then retransfected with the reporter plasmids as well as a second dose of siRNA to ensure persistence of the PTB knockdown. The DS9 transcript shows a high level of exon exclusion under normal conditions in HeLa cells as it did in HEK cells (Fig. 5, lane 2). This splicing repression is nearly completely eliminated by pretreatment of the cells with an siRNA that specifically targets PTB transcripts for degradation (Fig. 5, lane 4). The extent of PTB knockdown was $>90 \%$ as monitored by immunoblot with an anti-PTB antibody. The splicing repression was completely restored by expression of a PTB cDNA that is not targeted by the siRNA (Fig. 5, lane 6). Expression of this exogenous PTB was monitored with an antibody directed to the Flag epitope tag on the transfected PTB clone. Neither the siRNA nor the exogenous PTB affected the splicing of the parent DUP-175 construct, which does not contain PTB binding sites (Fig. 5, lanes 1,3,5). The loss of splicing repression upon loss of PTB expression, and its restoration with the complementing PTB CDNA, confirms that PTB is indeed the mediating factor in this regulation (Fig. 5, lanes $4,6)$.

\section{Flanking PTB sites repress exon splicing in vitro}

The src N1 exon is strongly repressed by PTB in vitro (Chan and Black 1997; Chou et al. 2000). However, other proteins that bind cooperatively with $\mathrm{PTB}$ also affect this exon (Markovtsov et al. 2000). To determine whether PTB-mediated repression could be observed in our minimal substrate in vitro we measured the splicing of the introns both upstream and downstream of the DUP-51 exon in both HeLa and WERI-1 nuclear extracts. A DUP-51 RNA substrate truncated in the second intron showed excision of the upstream intron in HeLa extract (Fig. 6A, lane 1). Replacement of the $\beta$-globin 3 ' splice site with the c-src PTB binding splice site led to partial inhibition of splicing, as it did in vivo (DS1-51, lane 2). In contrast, a PTB site downstream of the exon had little effect (DS4-51, lane 3). However, combining the upstream and downstream binding sites nearly abolished splicing (DS5-51, lane 4). In WERI- 1 extract, the parent DUP-51 exon spliced slightly less well than in HeLa (DUP-51, lane 5). This is also seen in vivo (data not shown). Interestingly, the PTB binding sites had a smaller effect on the splicing in this extract. Pre-mRNAs with a PTB binding site upstream of the test exon spliced somewhat less well than the wild type (DS151, lane 6), whereas the transcript containing both upstream and downstream PTB sites showed slightly higher levels of splicing than the wild-type RNA (DS5-51, lane 8). If either the HeLa or WERI extract was supplemented with recombinant $\mathrm{PTB}$, the splicing of the DS5-51 RNA was completely abolished (Fig. 6B, lanes $5-8$ ). In contrast this treatment had no effect on DUP-51 splicing (Fig. 6B, lanes $1-4)$.

Similar experiments were performed on the downstream intron (data not shown). This intron also spliced well in either extract, and when flanking PTB binding sites were added, splicing was strongly inhibited. Unlike the upstream intron, this downstream intron splicing is also inhibited in WERI extract (data not shown).
FIGURE 4. Two PTB-binding elements are needed to repress splicing of a reporter exon. $(A)$ The structure of DUP-175 minigenes containing various sequences from the src N1 3' splice site (175 indicates the number of the nucleotides in the reporter exon). The solid thin line represents $\beta$-globin intron sequences and the solid thick bar indicates src N1 3' splice site sequences. The different src sequences added to each construct are indicated to the right side. The 3' AG and the 5' GU dinucleotides at the reporter exon splice sites are indicated. Bp represents the $\beta$-globin branch point sequence. Pyrimidine deletions in the N1 3' splice site are indicated by inverted triangles. $(B)$ Primer extension analysis of the RNA isolated from HEK293 cells after transfection of each minigene. The position of the primer extension products for exon inclusion and exclusion are shown on the left. The name of each construct is indicated at the top. A truncated version of DUP4-1 (DUP4-1S; see Materials and Methods) was used as a control for transfection efficiency. $(C)$ Each primer extension product was quantified, using a Molecular Dynamics Typhoon PhosphorImager and ImageQuant software, and the percent exon exclusion was calculated (exon excluded product/exon excluded product plus exon included product). These results for the gel shown were plotted in the histogram. (D) DUP-51 minigene constructs (with a 51-nt reporter exon) were used to examine PTB-mediated splicing repression on an inefficiently spliced exon. The maps of the constructs are shown as in $A$. The transfection, primer extension, and quantification were performed as in $B$.

\section{Low affinity downstream sites induce cooperative assembly of multimeric PTB complexes and splicing repression}

Earlier studies showed that regulatory sequences on one side of the N1 exon could repress splicing of the intron on the opposite side and implied an interaction between the upstream and the downstream regulatory regions (Chan and Black 1995; Chou et al. 2000). However, it was not clear which proteins binding to the elements were interacting. The recapitulation of splicing repression in RNAs containing only PTB 


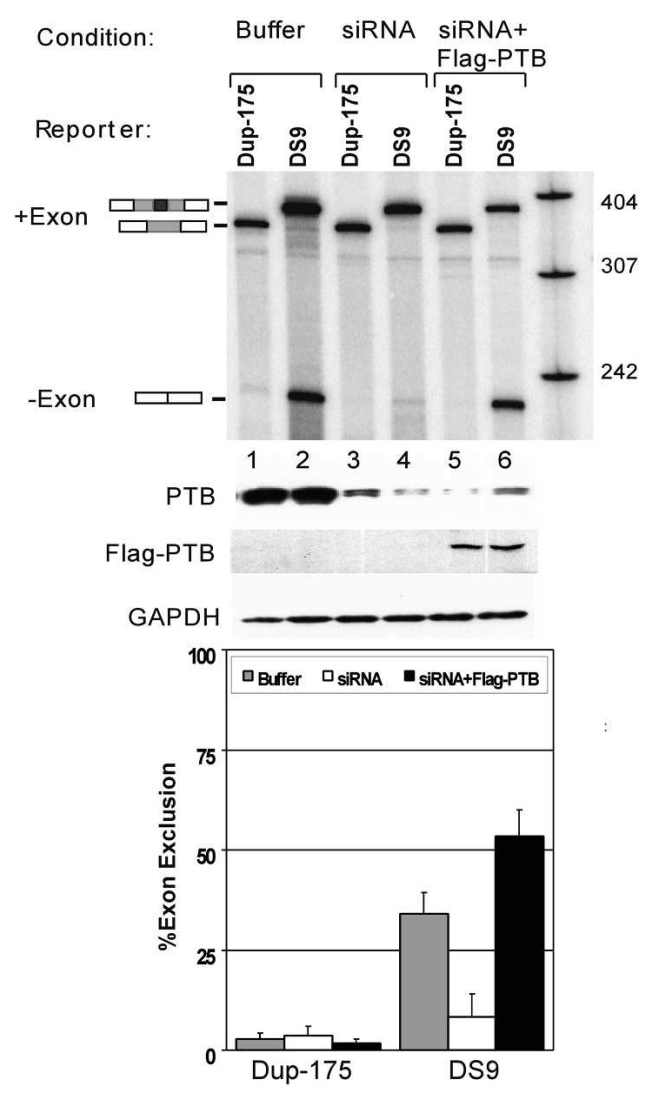

FIGURE 5. Splicing repression by CU elements is highly dependent on PTB expression. The DUP 175 and DS9 reporter constructs were transiently expressed in HeLa cells where PTB expression was knocked down with an siRNA and in similar cells expressing a complementing FLAG-PTB. Reporters were transfected with buffer (lanes 1,2), PTB siRNA plus empty pcDNA vector (lanes 3,4), and PTB siRNA plus Flag-PTB expression vector (lanes 5,6). The top panel shows RT-PCR analysis of splicing after transient expression of the constructs indicated with the products diagrammed on the left. Western blot analyses using BB7 antibody (anti PTB), anti-Flag tag antibody (anti-FLAGPTB), and anti-GAPDH confirmed the PTB expression level. These are shown below, aligned with the RT-PCR panel. Quantification of the splicing is shown in the histogram plotted as percent exon exclusion $(n=3)$. Calculation of exon exclusion is as in Figure 4C.

sites implies that this cross-exon interaction is mediated by PTB.

The high affinity PTB binding site within the N1 3' splice site binds to a single PTB at low concentrations of protein, but forms a higher order Complex 2 at high concentration. Efficient splicing repression requires the ability to form this Complex 2. However, in most cases, this site is not sufficient to induce splicing repression. Efficient splicing repression requires an additional downstream binding site. In the src pre-mRNA, the downstream PTB binding sites are much weaker than the upstream site and, at the protein concentrations used for Complex 1, do not bind PTB alone (Markovtsov et al. 2000). To study the cross-exon interaction between PTB molecules more directly, we examined the ability of this weak downstream sequence to affect the bind- ing of the recombinant protein to probes carrying the high affinity site.

We find that the weak PTB binding downstream sequence has a large effect on the affinity and stoichiometry of PTB binding in a gel shift assay. When the downstream elements were present in a probe carrying the high affinity upstream site, the formation of the monomeric complex occurred at about twofold lower PTB concentration than with the upstream site alone (Fig. 7A, cf. lanes 2 and 8). More strikingly, this complex was almost immediately converted into a multimeric complex as the protein concentration was increased (cf. lanes 3 and 9). Nearly all of the RNA probe was in a multimeric complex at $100 \mathrm{nM}$ of protein. This is $\sim 10$-fold less protein than was needed to convert the upstream site alone into Complex 2. This concentration is also lower than that needed to form a PTB complex on the downstream sequence alone (Markovtsov et al. 2000). The lower affinity PTB binding elements allow higher order complexes to form on probes carrying a high affinity site. If these downstream elements are mutated, the probe behaves more like the upstream site alone, forming higher order complexes only at higher concentrations of protein (Probe I, lanes 13-18). With these longer probes, the gel shift complexes are more smeared and heterogeneous, and, as the protein concentration is increased, Complex 2 is converted into still larger complexes apparently containing additional PTB molecules (Fig. 7A, lane 12). These data suggest that PTB alone can mediate an exon bridging interaction, and that the multimeric PTB Complex 2 is the structure that can efficiently silence splicing. The structure of these large complexes and the interactions of PTB within them will be an interesting avenue for investigation.

The preceding binding experiments imply that the downstream PTB binding sites can be shorter, lower affinity elements than the upstream site and still yield splicing repression. To test this, we added either just one or two CUU CUCUCU repeats into the downstream position. Both of these elements increased exon skipping relative to the upstream site alone (Fig. 7B). DS 15 transcript in particular, containing two repeats, showed a greater than fourfold increase in exon skipping over the transcript with the upstream site alone. This downstream element shows only weak complex formation and nearly no Complex 2 and yet is sufficient to mediate the inhibition by the upstream site. Thus for splicing inhibition, the PTB interactions at the upstream and downstream sites need not be equivalent. The inhibitory complex is likely similar to Complex 2 or a larger structure rather than two complete high affinity complexes flanking the exon.

\section{DISCUSSION}

\section{Mechanisms of PTB-mediated splicing repression}

We have determined the minimum requirements for PTBmediated repression of an alternative exon. First, using a 
A
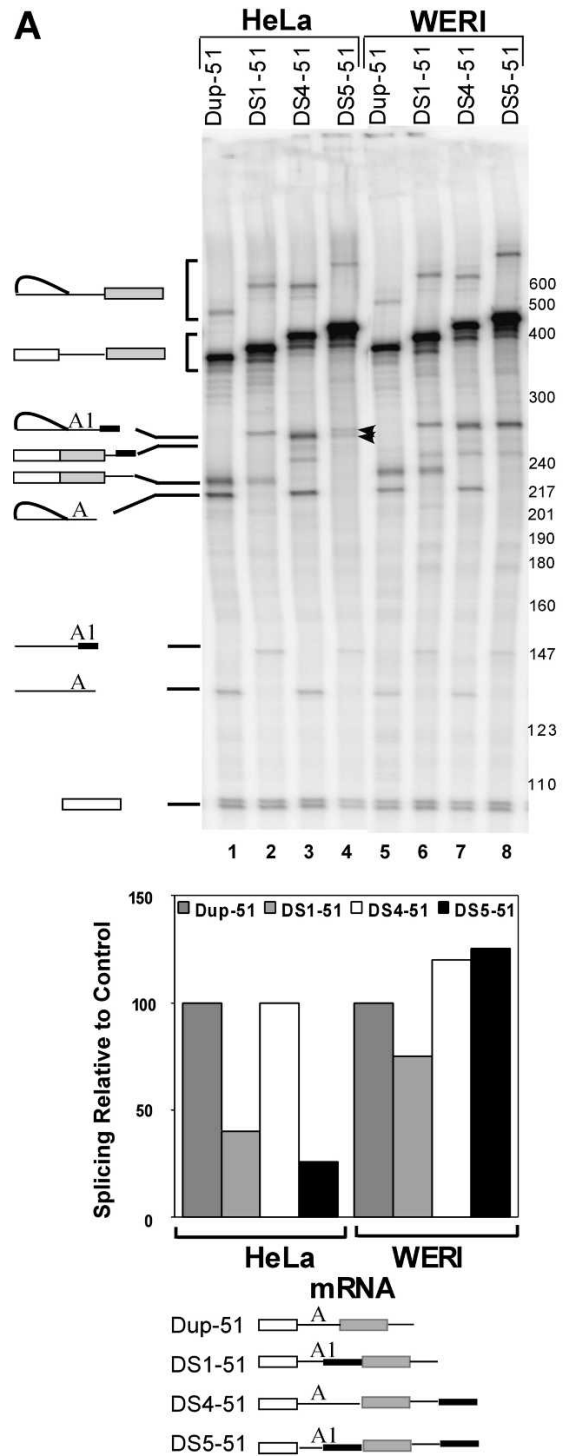

B
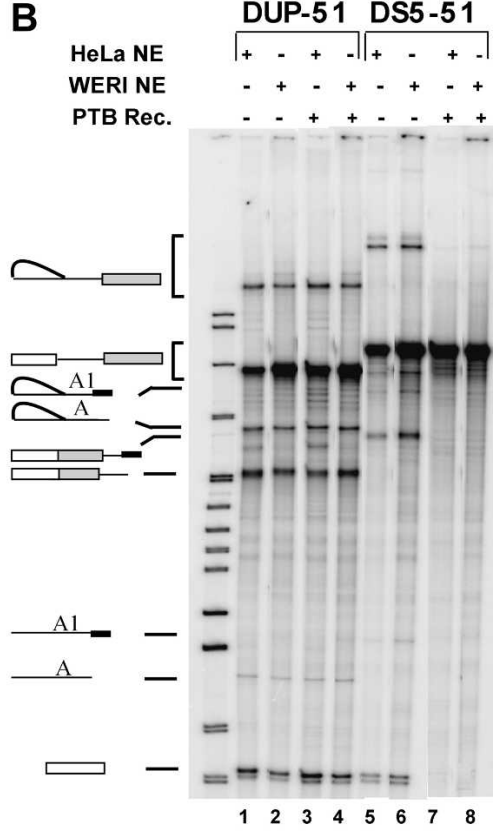

FIGURE 6. PTB binding elements are sufficient to repress splicing in vitro. (A) $\beta$-Globin transcripts with or without PTB binding elements are diagrammed at the lower left. These are equivalent to those in Figure 4D except that they have a T7 promoter in place of the CMV promoter and are truncated within the downstream intron. This allows the assay of the upstream intron A or A1. RNA from these clones was incubated in an in vitro splicing reaction containing HeLa or WERI nuclear extract and resolved on the gel. The positions of two lariats, the unspliced precursor, the spliced product, and the $5^{\prime}$ exon intermediate for each transcript are diagrammed to the left of the gel. The positions of intron A, which is the product of DUP-51 and DS4-51, and of intron A1, which is the product of the DS1-51 and DS5-51, differ due to the different $3^{\prime}$ splice sites in these clones. Similarly the mRNAs for DUP-51 and DS1-51 (235 nt) are shorter than the mRNAs for DS4-51 and DS5-51 (271 nt) due to the downstream PTB sites in the latter RNAs. The double arrow head indicates the position of the intron A1 lariat and the DS5-51 mRNA just below it. Quantification of the spliced mRNA product relative to the DUP51 control is shown in the histogram below. (B) Added PTB eliminates splicing of CU element carrying RNA. The DUP-51 and DS5-51 transcripts were added to splicing reactions containing HeLa (lanes 1,3,5,7) or WERI nuclear extract (lanes 2,4,6,8). In some reactions recombinant PTB (80 ng, $50 \mathrm{nM}$ final concentration) was also added (lanes 3,4,7,8). Note that PTB strongly inhibits the DS5-51 splicing, but not DUP51.

variety of binding assays, we delineated a minimum high affinity binding site for the protein. This encompasses more than $30 \mathrm{nt}$ of RNA, requiring two copies of the CUUCU

CUCU element as well as adjacent pyrimidine nucleotides. Ultracentrifugation analyses indicate that initial binding of this site is likely by a PTB monomer. Boundary mapping indicates that in Complex 1 a PTB monomer interacts with one CUUCUCUCU repeat plus four to six additional pyrimidines on each side. By mapping RNA cross-links onto the protein sequence, we show that nucleotides across a single CUUCU CUCU repeat contact RRM 4 of PTB, while the $5^{\prime}$ most $U$ is proximal to RRM 1 . The adjacent pyrimidines are presumably contacting other portions of the protein. At high concentrations of protein, additional PTB molecules can assemble onto the extended binding site to form Complex 2. This binding is lower affinity, encompasses less RNA sequence, and is hence not an equivalent contact to the first PTB monomer.

Having defined a PTB binding site, we determined the elements that were sufficient to mediate PTB-dependent splicing repression of an exon. For a weakly spliced exon, some repression can occur with a single high affinity site. This may or may not be placed within the $3^{\prime}$ splice site of the repressed exon, where it could interfere with U2AF65 binding. An efficiently spliced exon can also be highly repressed by PTB. However, this requires at least two PTB binding sites with the upstream site long enough to form Complex 2. Neither site need be in the 3' splice site; an exon with a PTB site upstream of the branch point and another within either the exon or the downstream intron is repressed for splicing. Thus, PTB binding need not be in direct competition with U2AF to repress splicing. Instead, for a standard well-spliced exon, PTB-mediated repression requires multiple binding sites and the ability to assemble a multimeric complex.

Studies of other systems have generally found multiple PTB binding sites in the region of the repressed exon (Wagner and Garcia-Blanco 2001). These systems are presumably similar to the multiprotein mechanism described here. However, there are examples where only a single binding site is known and in some cases this single site seems to be sufficient to mediate 


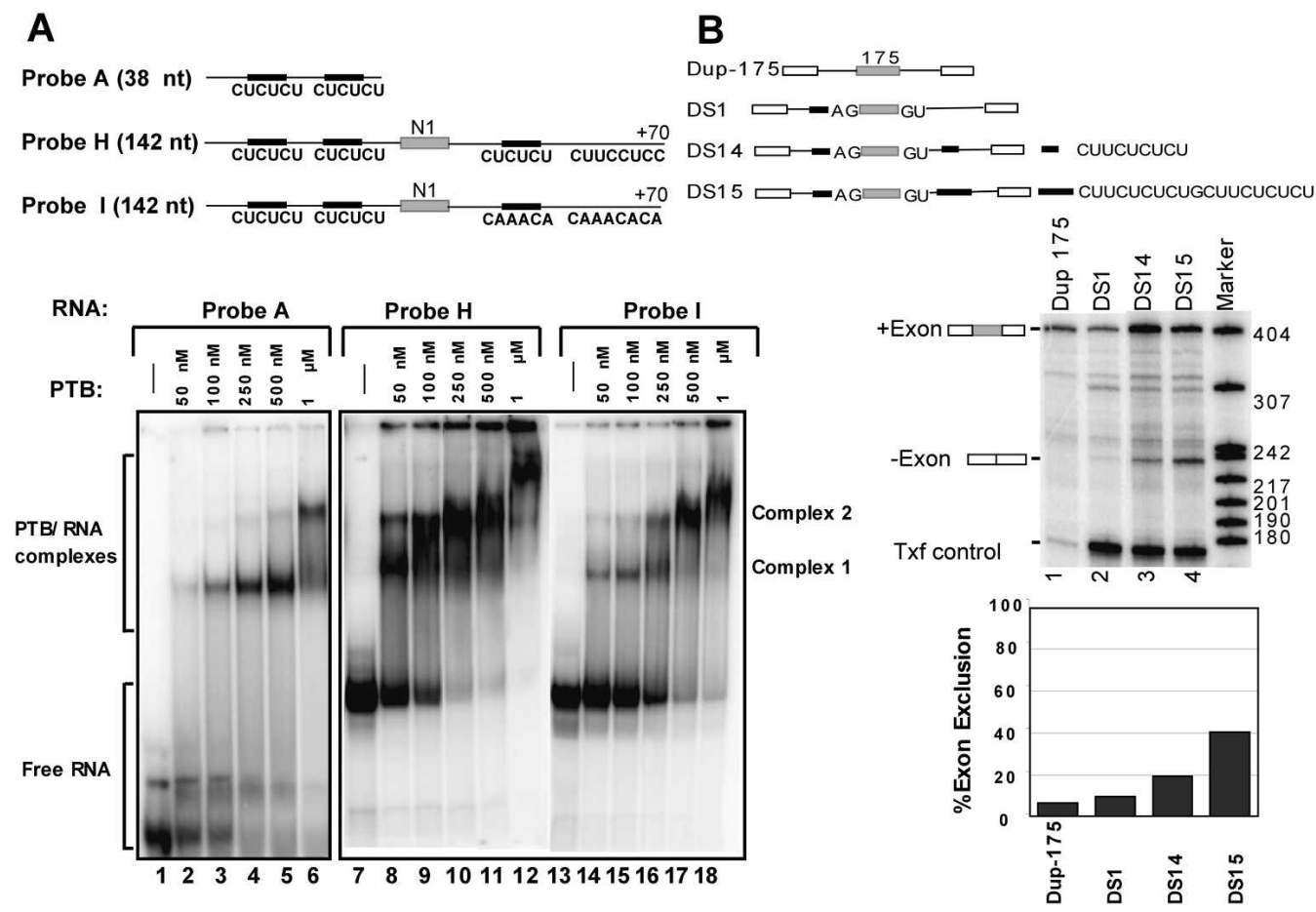

FIGURE 7. Weak downstream PTB sites stimulate Complex 2 formation and splicing repression. (A) Probe A contains the N1 exon 3' splice site. Probe $\mathrm{H}$ contains this same sequence, as well as the N1 exon and the weak downstream PTB binding sites. Probe I is the same as Probe H except that two of the CU elements in the downstream intron are mutated as shown below. EMSA was performed on each probe with increasing amounts of PTB protein (indicated at the top). Note that Complex 2 (labeled at the right) forms on Probe $\mathrm{H}$ at a much lower PTB concentration than on the other two probes. (B) Primer extension analysis of RNA from HEK-293 cells after transient expression of the minigenes indicated. The position of the spliced products is shown on the left. DS14 and DS15 contain one and two downstream CUUCUCUCU elements, respectively (diagrammed at the top). Each primer extension product was quantified as in Figure $4 \mathrm{C}$ and plotted on the histogram shown.

repression (Shen et al. 2004). Within an exon, PTB may block exonic splicing enhancer function or some other step of exon definition (Shen et al. 2004). Some exons may also have additional unidentified PTB binding sites. These could be relatively short pyrimidine elements that are not as easily recognized as a longer high affinity site. From the results presented here, one would predict that exons that can be repressed by a single PTB site are already weak in their recognition of constitutive factors.

Diverse and often unrecognized regulatory elements are a confounding issue for understanding systems of tissue-specific splicing. Although particular RNA elements can be shown to be required for regulation, it is often difficult to assess which elements are sufficient or which are the most important determinants of tissue specificity. To simplify the analysis of PTB-mediated regulation, we started with a constitutive exon and asked if it could be repressed only by adding PTB sites. Although one cannot be sure there are no unknown elements in this exon that allow its repression by PTB, the resulting exon is highly PTB dependent.

The development of reporters where splicing repression is dependent only on PTB sites allows the direct comparison of cell lines for PTB activity. For example, we found previously that WERI-1 cells splice the src N1 exon more efficiently than HeLa cells. This exon is repressed by PTB in
HeLa cells, but is affected by numerous other elements as well. We find here that when DUP reporter constructs are expressed in WERI cells or incubated in WERI nuclear extracts, they show less splicing repression than in HeLa or HEK cells (Fig. 6; data not shown). Since these RNAs are presumably only dependent on PTB for repression, this indicates that the tissue specificity of exon splicing seen in WERI cells is due to a loss of PTB activity. We hope to now use this system to examine the mechanism of this reduced PTB activity. WERI cells contain significant amounts of PTB protein, but also contain $\mathrm{nPTB}$, which also binds to the repressor elements. Future experiments will use the PTBrepressed substrates to examine how $\mathrm{nPTB}$ might differ in activity.

\section{The structure of PTB/RNA complexes}

In earlier work, PTB was described as a dimer in solution, based on size exclusion chromatography, yeast two-hybrid interactions, and protein/protein cross-linking (Pérez et al. 1997b; Oh et al. 1998). Thus, we first hypothesized that a PTB dimer would interact with the duplicated pyrimidine element in the PTB binding site of the N1 exon 3' splice site. However, we found that the initial binding of PTB to form Complex 1 does not involve both repeats, as would be 
expected if each half of a dimer made equivalent interaction with one repeat. Thus, we reexamined the molecular weight of PTB in solution by analytical ultracentrifugation. This analysis gives an apparent molecular weight for the protein as $61 \mathrm{kDa}$, much closer to the $58-\mathrm{kDa}$ monomer than a dimer. Recent results from Simpson et al. (2004), using both analytical centrifugation and low angle $\mathrm{x}$-ray scattering, also indicate that PTB is primarily monomeric in solution and are in good agreement with what we observe. Thus Complex 1, forming at low protein concentrations, represents the binding of a single PTB molecule. Rather than interacting with a dimer, the duplicated pyrimidine element presumably yields higher affinity binding by offering greater conformational choices in binding and allowing protein binding in multiple registers along the RNA, as was proposed for U2AF65 (Banerjee et al. 2003). The observed $\mathrm{S}$ value of 3.3 is lower than expected for a $60-\mathrm{kDa}$ sphere, indicating that the protein does have an irregular shape that could result in its anomolous mobility by gel filtration. This unusual shape is also supported by NMR observations that in full-length protein, RRMs 1 and 2 are each behaving independently in solution from the RRM 3-4 portion (F. Allain, pers. comm.). The previous results on dimerization could stem from a limited population of protein engaged in a homomeric interaction. The hydrodynamic measurements are also consistent with a small fraction of the protein existing as aggregates in solution (data not shown). This could be the source of the protein/protein cross-links observed previously (Oh et al. 1998). However, the protein clearly assembles into multimeric complexes on the RNA, and homomeric protein/protein interactions between PTB molecules likely occur within these RNP complexes. Resolving the nature of these dimerization contacts will be a question for the future.

The role of the different protein domains in these complexes is also an interesting question. We find that in binding to a CUUCUCUCU repeat, the protein contacts RNA with both RRMs 1 and 4. This is consistent with previous results examining RNA binding of individual domains, but does not rule out RNA contacts with the other two domains (Pérez et al. 1997b; Liu et al. 2002). Earlier work showed that the RRM 3-4 fragment had much higher affinity for RNA than RRM 4 alone (Pérez et al. 1997b). RRMs 2 and 3 could contact the additional pyrimidines outside of a single repeat that are also needed for binding. Studies of PTB regulation of the $\mathrm{GABA}_{\mathrm{A}}$ receptor indicated that portions of RRM 4 were not required for stable binding but were needed for splicing repression (Liu et al. 2002). In that system, the RNA is likely making RNA contacts in addition to those in RRM 1. An understanding of the structure of the PTB protein in its interaction with an extended pyrimidine tract is needed to resolve the role of the other RRMs.

The binding data indicate that PTB can engage in more than one mode of binding to RNA. On the long, high affinity site, the initial complex encompasses more than half the available RNA. When the second protein binds, there is not room to engage the same number of nucleotides, and this protein binds with much lower affinity. Interestingly when the short downstream binding sites are included in the RNA, the apparent affinity of this second complex greatly increases. Thus, this second protein may contact shorter pyrimidine elements that are more dispersed. For splicing repression, the high affinity site is not sufficient and requires these additional downstream elements. Since RRMs 1 and 4 are contacting the CUUCUCUCU repeat, it will be interesting to examine the role of the other RRMs in binding shorter, more widely dispersed elements in complexes containing the second PTB protein (Fig. 8).

The enhancement of higher order complex formation seen with RNAs containing two binding sites, and the requirement for an upstream site in blocking downstream intron splicing (and vice versa), imply communication between the proteins bound upstream and downstream of the exon. Earlier studies that identified these interactions used substrates that contained the whole intronic splicing enhancer downstream of the repressed exon (Chan and Black 1995; Chou et al. 2000). This sequence assembles a large complex of proteins, some of which cooperate with PTB in RNA binding. Thus, it was not possible to determine

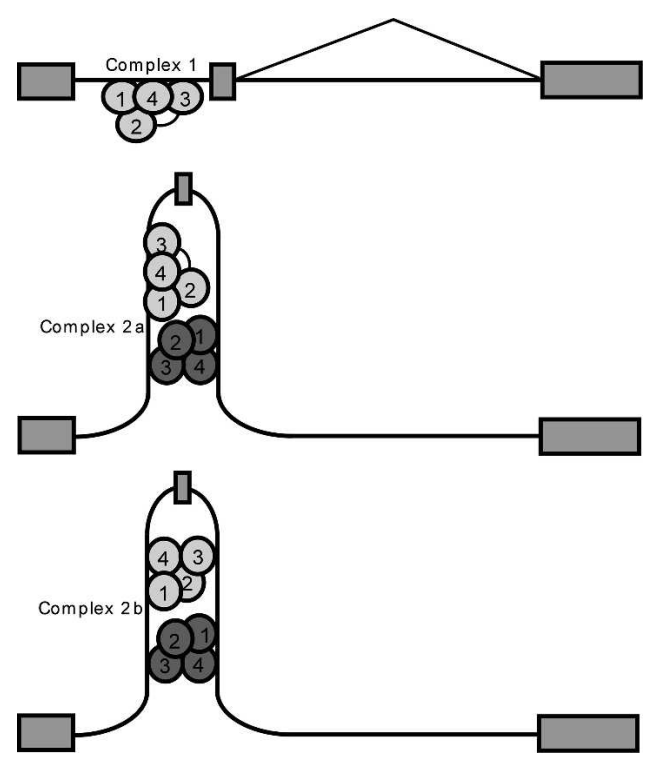

FIGURE 8. Models for the multimeric PTB complexes that repress splicing. In Complex 1 (top) one PTB molecule contacts a single CUU CUCUCU RNA element with both RRM 1 and 4. RRM 3 may contact additional RNA in that vicinity or not. This complex does not inhibit splicing. Complex 2 contains two PTB monomers. One is bound at the upstream high affinity site as in Complex 1, using RRMs 1 and 4. The second PTB engages the downstream CU elements, presumably also using RRMs 1 and 4. This PTB also makes a lower affinity contact with the upstream site, perhaps with RRMs 2 or 3. Different arrangements of CU elements may lead to different orientations of the PTB protein such as in Complex 2b. There are other feasible models than those shown. Note that there are likely dimerization interactions between the two PTB monomers that are not shown. These may occur between the RRM 2 domains as proposed (Pérez et al. 1997b). 
whether the cross-exon interactions were due to a direct interaction between upstream and downstream PTB molecules. The reconstruction of this interaction using just PTB sites and purified PTB indicates that at least part of the exon-bridging interaction is mediated only by PTB. The nature of this exon-bridging complex is very interesting. It is possible that a PTB monomer is bound on each side, and a protein/protein interaction results in a dimer. However, the additional RNA bound in Complex 2 and the ability of short elements to work as the second binding site point to an arrangement where different RRMs of a PTB monomer are engaged with separate binding sites, to form a bridge between them. If RRMs 1 and 4 make initial contact with one site, then perhaps RRMs 2 or 3 engage in the bridging interaction. Beside the roles of these RRMs, another question is whether the two PTB molecules in Complex 2 will both bridge the two sites, forming essentially equivalent contacts. Alternatively, there may be one protein fully engaged on one site and one protein forming the bridge. Two of several possible models for the arrangement of the multiple RRMs in the bridging complex are shown in Figure 8.

Besides PTB, the other well-characterized mammalian splicing repressor protein is hnRNP Al. This protein also has several proposed mechanisms for mediating splicing repression (Black 2003). Single exonic A1 binding sites can apparently block the function of exonic splicing enhancers or the binding of general splicing factors (Del Gatto-Konczak et al. 1999; Tange et al. 2001; Zhu et al. 2001; Kashima and Manley 2003; Zahler et al. 2004). Alternatively, in regulating an exon in its own transcript, multiple Al binding sites are needed that flank the repressed exon (Blanchette and Chabot 1997, 1999; Hutchison et al. 2002). In this A1 autoregulation, the multiple binding sites are proposed to allow the looping out of the exon by a multimeric A1 complex. In another system, A1 is thought to initiate binding at a high affinity site, and then nucleate additional non-sequence-specific A1 binding along the RNA, creating a region of protein-coated RNA refractory to other factor binding (Zhu et al. 2001). Behavior similar to two of these models is also seen with PTB: interference with enhancer function by a strategically placed PTB site and RNA looping between multiple PTB sites. The final A1 model does not seem likely with PTB, as nucleation of nonspecific binding would result in very large complexes observed in gel shift assays. Instead, although there are complexes containing more than two proteins, the observed multimeric PTB complexes are fairly discrete and contain a limited number of PTB monomers.

The complexity of natural systems of alternative splicing makes the study of their regulatory mechanisms difficult. Many different interdependent proteins affect each splicing choice. The reconstruction of splicing regulation to involve only PTB will allow us to examine PTB function in more mechanistic detail. In the future, this model system can be studied for PTB effect's on spliceosome assembly, differ- ences in PTB activity among cell types, the role of nPTB, and, perhaps most immediately, the structure of the multimeric PTB complex.

\section{MATERIALS AND METHODS}

\section{Plasmid constructs}

The pDup-51 and plasmids were described previously (Dominski and Kole 1991), with the modifications described for pDup4-1 (Modafferi and Black 1997). These plasmids were further modified to include an EagI restriction site in the middle of each test exon and a KpnI site $16 \mathrm{nt}$ downstream of the second exon. The c-src sequences were added to each Dup plasmid using oligonucleotidedirected PCR and inserting into these new sites. All constructs were confirmed by sequencing. The in vitro splicing templates were made by PCR using these plasmids and the T7-DUP8 oligonucleotide (5'-GGGTAATACGACTCACTATAGGACACCATGC ATGGTGCACCTG-3') as a $5^{\prime}$ primer and a src-specific $3^{\prime}$ primer. The resulting PCR products were used as templates for in vitro T7 RNA polymerase transcription. The RNA probes for RNA binding assays were made using similar PCR-derived T7 templates, from previously described plasmids, or they were synthetic RNA oligonucleotides (Dharmacon). The PTB-1 (accession no. X62006.1) and PTB-4 (accession no. X65372.1) constructs were derived from CMV-PTB-1 and CMV-PTB-4 plasmids (a generous gift from Chris Smith, Department of Biochemistry, University of Cambridge, Cambridge, United Kingdom). The FLAG-PTB for protein expression was made by adding a FLAG epitope tag at the Nterminus of the human PTB-4 coding sequence by PCR and cloned into pcDNA 3.1 at the EcoRI and BamHI sites. Dup4-1S, which was used as a transfection control in primer extension experiments, was made by digesting DUP4-1 with NsiI (which cuts in the middle of first exon and the beginning of second exon) and ligated back together. This made the spliced mRNA product of the DUP4-1S shorter than that of DUP4-1, allowing them to be distinguished on a gel.

\section{Gel mobility shift and filter binding analysis}

Each gel mobility shift reaction $(10 \mu \mathrm{L})$ contained $6 \mu \mathrm{L}$ binding buffer (20 mM HEPES at pH 7.6, 20\% glycerol, $80 \mathrm{mM}$ potassium glutamate, $100 \mathrm{ng} / \mu \mathrm{L}$ tRNA, $0.02 \% \mathrm{NP} 40,6 \mathrm{mM} \mathrm{MgCl}_{2}, 1 \mathrm{mM}$ DTT) plus recombinant PTB $(50 \mathrm{nM}-1 \mu \mathrm{M})$. All reaction components except RNA probe were mixed and incubated for $8 \mathrm{~min}$ at $30^{\circ} \mathrm{C}$; the RNA probe $(50,000 \mathrm{cpm}, \sim 10 \mathrm{fmol})$ was then added and incubated for an additional $15 \mathrm{~min}$. The reactions were put on ice for $5 \mathrm{~min}$ and then were separated on an $8 \%$ native polyacrylamide gel. The apparent $K_{d}$ was estimated as the concentration of protein where the RNA was half bound.

Nitrocellulose filter binding assays were carried out as described with some modifications (Liu et al. 2002). The recombinant PTB (10 nM to $1 \mu \mathrm{M}, n=3$ for each PTB concentration) were incubated with $1 \mathrm{fmol}$ of ${ }^{32} \mathrm{P}$-labeled RNA in $50 \mu \mathrm{L}$ binding buffer

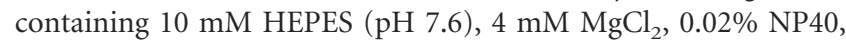
$100 \mathrm{ng} / \mu \mathrm{L}$ tRNA, $5 \mathrm{mM}$ DTT, and $50 \mathrm{mM}$ potassium glutamate and incubated at $30^{\circ} \mathrm{C}$ for $20 \mathrm{~min}$. Reactions were then diluted with $450 \mu \mathrm{L}$ binding buffer and filtered through $0.45 \mu \mathrm{M}$ nitrocellulose filters (Millipore) in a Millipore 1225 vacuum manifold. Filters were washed four times with binding buffer, dried, and the 
RNA retained on each filter was measured by scintillation counting. The fraction bound RNA was calculated as RNA retained on the filter/total RNA. The apparent $K_{d}$ values were determined by fitting the data to the expected curves for one binding site $[y=m 1 \times x /(m 2+x) ; m 1=B \max$ (total amount of binding), $m 2=K_{d}, \quad x=$ protein concentration] or two binding sites $[y=m 1 \times x /(m 2+x)+m 3 \times x /(m 4+x) ; \quad m 1=B \max 1, \quad m 2=$ $K_{d} 1, m 2=B \max 2, m 4=\mathrm{K}_{\mathrm{d}} 2, x=$ protein concentration], using KaleidaGraph (Synergy) software.

\section{RNA labeling and alkaline hydrolysis}

Five picomoles of RNA probe were phosphorylated at its $5^{\prime}$ end using $\left[\gamma_{-}{ }^{32} \mathrm{P}\right]$ ATP and polynucleotide kinase (New England Biolabs) according to standard protocols and gel purified.

For $3^{\prime}$-end labeling, 10 pmol of RNA were incubated with 20 pmol 5' ${ }^{32} \mathrm{P}$ pCp (specific activity $3000 \mathrm{Ci} / \mathrm{mmol}$ ) and T4 RNA ligase (New England Biolabs) in a $10-\mu \mathrm{L}$ reaction (England et al. 1980). Partial alkaline hydrolysis was carried out in $10 \mu \mathrm{L}$ of $3^{\prime}$ - or 5'-end-labeled RNA $\left(10^{6} \mathrm{cpm}\right), 50 \mathrm{mM} \mathrm{NaHCO}, 50 \mathrm{mM}$ $\mathrm{Na}_{2} \mathrm{CO}_{3}$, carrier tRNA $(1 \mathrm{mg} / \mathrm{mL})$, and $1 \mathrm{mM}$ EDTA (pH 9.2). These were incubated at $80^{\circ} \mathrm{C}$ for $10 \mathrm{~min}$ to generate a ladder of hydrolysis products, neutralized with $\mathrm{HCl}$, extracted with phenolchloroform, and ethanol precipitated. Boundary mapping (Bevilacqua et al. 1998) was performed by incubating the hydrolyzed RNA in binding buffer with $1 \mu \mathrm{M}$ PTB (above) followed by separation of the RNA-PTB complexes on an $8 \%$ native polyacrylamide gel. The RNA was then eluted from Complex 1 and Complex 2 and the RNA ladder from each complex was separated on an $8 \%$ denaturing polyacrylamide gel. To make the G-position marker, the $5^{\prime}$-end-labeled RNA was partially digested with 0.1 unit RNAse $\mathrm{T} 1$ (Ambion) for $5 \mathrm{~min}$ at $37^{\circ} \mathrm{C}$ and digestion was stopped by adding an equal amount of formamide gel loading buffer.

\section{RNA for cross-linking and proteolysis experiments}

$\alpha-{ }^{32} \mathrm{P}$ UTP radioactively labeled RNA probe was obtained by in vitro transcription using the BS7 template cut with Bsu36I. 4-Thiouridine was incorporated into the BS7/Bsu36I RNA by replacing UTP with 4-thio-UTP (a generous gift from A. Mustaev, Public Health Research Institute) in the transcription reaction. Short synthetic RNAs containing single 4-thiouridine substitutions, as well as the CUCUCU RNA oligo, were obtained from Dharmacon. These were 5 '-end labeled using T4 polynucleotide kinase (NEB) according to standard protocols. After labeling, each RNA probe was gel purified under denaturing conditions to remove unincorporated nucleotides as well as any degraded RNA. Bacterially expressed recombinant His6-tagged PTB was purified using Ni-NTA agarose. In a typical cross-linking experiment, $3 \mu \mathrm{g}$ of PTB were mixed with RNA $\left(2 \times 10^{5} \mathrm{cpm}\right.$ for the BS7 probe and $2 \times 10^{4} \mathrm{cpm}$ for short RNAs) in binding buffer containing $20 \mathrm{mM}$ Tris ( $\mathrm{pH} 7.5$ ), $50 \mathrm{mM} \mathrm{NaCl}$, and $10 \mathrm{mM} \mathrm{MgCl}_{2}$ and incubated for $5 \mathrm{~min}$ at room temperature. Cross-linking was performed on ice in $254 \mathrm{~nm}$ UV light for unsubstituted RNA or in $366 \mathrm{~nm}$ UV light for 4-thiouridine substituted RNA, using hand-held lamps for $30 \mathrm{~min}$. In the case of the BS7 templates, cross-linking was followed by a 1-h treatment with a mixture of $1 \mu \mathrm{g}$ of RNAse A (Ambion) and 250 units of RNAse $\mathrm{T} 1$ (Ambion) at $37^{\circ} \mathrm{C}$ to reduce the crosslinked RNA to short oligonucleotides.

\section{Proteolysis and $\mathrm{CNBr}$ cleavage}

For exhaustive proteolysis, the cross-linked protein was digested overnight with either Glu-C, Asp-N, Lys-C, or trypsin (all enzymes are sequencing grade; Roche Molecular Biochemicals) alone or in combination according to the manufacturer's specifications at a PTB to enzyme ratio of 20:1 (w/w). Digested PTB was then analyzed by electrophoresis on 16\% Tris-tricine gels (Novex). For partial proteolysis, a ratio of 50:1 (PTB:enzyme) was used. The reactions were stopped by adding SDS sample buffer at the indicated times, quickly followed by heating the sample (boiling for $254 \mathrm{~nm}$ cross-linking or $37^{\circ} \mathrm{C}$ for $366 \mathrm{~nm}$ cross-linking) prior to gel loading.

For CNBr cleavage, the cross-linked protein was gel purified on an $8 \%$ Tris-glycine gel (Novex). The gel slice containing labeled PTB was excised from the gel, washed twice with $1 \mathrm{~mL}$ of water to remove the buffer, crushed, and the protein was eluted in three volumes of $0.3 \%$ SDS at $37^{\circ} \mathrm{C}$ for $1 \mathrm{~h}$. The supernatant was separated from the gel pieces by centrifugation in a microspin column (Biorad), flash frozen, and lyophilized on a SpeedVac. Partial and exhaustive $\mathrm{CNBr}$ cleavages were then performed according to previously published protocols (Grachev et al. 1987, 1989). The exhaustive $\mathrm{CNBr}$ cleavage reaction mixture was diluted 10-fold with water, flash frozen, and lyophilized completely using a SpeedVac to remove the formic acid. The dry residue was washed with $70 \%$ ethanol to remove SDS and then redissolved in immunoprecipitation buffer $(50 \mathrm{mM}$ Tris- $\mathrm{HCl}$ at $\mathrm{pH} 7.5,150 \mathrm{mM} \mathrm{NaCl}, 0.05 \%$ Triton X-100). Twenty microliters of Protein A beads were equilibrated with the IP buffer, blocked with $1 \mathrm{~mL}$ of $1 \mathrm{mg} / \mathrm{mL}$ BSA for $1 \mathrm{~h}$ at $4^{\circ} \mathrm{C}$ and then incubated with $25 \mu \mathrm{L}$ of corresponding serum. After extensive washes with IP buffer, the $\mathrm{CNBr}$ cleavage products were added and followed by a $3 \mathrm{~h}$ incubation at $4^{\circ} \mathrm{C}$. The unbound peptides were removed with four 1-mL washes of IP buffer. The bound peptides were eluted with $50 \mu \mathrm{L}$ of $1 \times$ SDS sample buffer and loaded onto a 16\% Tris-tricine gel. The gels were dried and autoradiographed on a Typhoon PhosphorImager (Molecular Dynamics).

\section{Analytical ultracentrifugation}

Sedimentation velocity experiments were performed in a Beckman Optima XL-A analytical ultracentrifuge at 55,000 rpm and $20^{\circ} \mathrm{C}$ using absorption optics at $280 \mathrm{~nm}$ and a $12-\mathrm{mm}$ path length double sector cell. The PTB was at $1.8 \mathrm{mg} / \mathrm{mL}$ in $80 \mathrm{mM} \mathrm{KCl}, 6$ $\mathrm{mM}$ magnesium acetate, $20 \mathrm{mM}$ HEPES ( $\mathrm{pH}$ 7.6). The sedimentation coefficient distribution was determined from a differential sedimentation coefficient plot $(g(s))$ using the Beckman Originbased software (version 3.01). The peak sedimentation coefficient was corrected for density and viscosity to an $S_{20, w}$ value using a value for the partial specific volume at $20^{\circ} \mathrm{C}$ of 0.739 , calculated from the amino acid composition of PTB (Cohn and Edsall 1943) and corrected to $20^{\circ} \mathrm{C}$ (Laue et al. 1992). Sedimentation equilibrium experiments were performed on PTB $(0.44 \mathrm{mg} / \mathrm{mL})$ in 80 $\mathrm{mM} \mathrm{KCl}, 6 \mathrm{mM}$ magnesium acetate, $20 \mathrm{mM}$ HEPES ( $\mathrm{pH}$ 7.6) at $4^{\circ} \mathrm{C}$ and rotor speeds of $12,000 \mathrm{rpm}$, again on a Beckman Optima XL-A analytical ultracentrifuge with absorption optics at $280 \mathrm{~nm}$. A partial specific volume of 0.734 , calculated as described above, was used. Individual scans were analyzed using the Beckman Origin-based software (version 3.01) to perform a nonlinear least- 
squares exponential fit for a single ideal species to give the weightaverage molecular weight.

\section{Cell culture, transfection, and RNA preparation}

Transfection experiments were carried out as previously described (Modafferi and Black 1997). For transfection, $4 \mu \mathrm{g}$ of DNA were transfected into each well of a six-well plate (50\% confluence) using Lipofectamine 2000 (Invitrogen) according to the manufacturer's instructions. Cytoplasmic RNA was prepared $48 \mathrm{~h}$ after transfection as described (Modafferi and Black 1997).

\section{SiRNA and expression of exogenous FLAG-PTB}

The siRNA target sequence in PTB comprises nucleotides 16871707 (5'-AGACCAGAGATTTTATTTTTT-3') in the $3^{\prime}$ UTR of human PTB. The siRNA sense sequence is $5^{\prime}$-ACCAGAGAUUU UAUUUUUUUU-3' and the antisense siRNA sequence is $5^{\prime}$-AA AAAAUAAAAUCUCUGGUCU-3' with 19-nt complementarity and a 2-nt overhang at each $3^{\prime}$ end. The siRNA was synthesized by T7 transcription on DNA templates designed to make each siRNA strand. For each siRNA strand, the template was made by hybridizing an oligo with a T7 primer and 8-nt universal sequence and the sense or antisense strand template oligo containing the complement of the 8 -nt universal sequence at its $3^{\prime}$ end. The sense template oligo was $5^{\prime}$-AAAAAATAAAATCTCTGGTCCTGTCTC$3^{\prime}$, the antisense template oligo was 5'-AGACCAGAGATTTTAT TTTTTCCTGTCTC- ${ }^{\prime}$, and the sequence of the T7 promoter primer was 5'-TAATACGACTCACTATAGGGAGACAGG -3'. To obtain each siRNA strand, DNA templates were hybridized and made fully double stranded by exo-Klenow fill-in (NEB). The templates were used in transcription reactions to synthesize sense and antisense RNA separately (Milligan et al. 1987). After transcription, the siRNA reactions were mixed and incubated at $37^{\circ} \mathrm{C}$ overnight to hybridize the sense and antisense strands. The reaction mixture was digested with DNase I (25 U; Roche) and RNAse T1 (3000 U; Ambion) in DNase I digestion buffer $(20 \mathrm{mM}$ Tris- $\mathrm{HCl}$ at $\mathrm{pH} 8.4,2 \mathrm{mM} \mathrm{MgCl} 2,50 \mathrm{mM} \mathrm{KCl})$ for $2 \mathrm{~h}$ at $37^{\circ} \mathrm{C}$. RNA was extracted with phenol:choloroform:isoamyl alcohol (25:24:1), precipitated in ethanol, and the final siRNA concentration was adjusted to $20 \mu \mathrm{M}(0.3 \mu \mathrm{g} / \mu \mathrm{L})$ in dsRNA hybridization buffer $(20$ mM HEPES, $\mathrm{KOH}$ at $\mathrm{pH}$ 7.6, $\left.50 \mathrm{mM} \mathrm{KoAc,} 1 \mathrm{mM} \mathrm{Mg}(\mathrm{oAc})_{2}\right)$.

HeLa cells were grown to $90 \%$ confluency and transiently transfected with $2 \mu \mathrm{L}$ of siRNA duplex $(20 \mu \mathrm{M}), 0.5 \mu \mathrm{g}$ empty expression vector, and $2 \mu \mathrm{g}$ pUC 18 added to Opti-MEM (Invitrogen) in a six-well plate using Lipofectamin 2000 (Invitrogen) as per the manufacturer's protocol. After $48 \mathrm{~h}$, the transfection was repeated with $3 \mu \mathrm{g}$ total DNA containing the reporter and expression plasmids $(0.5 \mu \mathrm{g}$ splicing reporter construct, $0.5 \mu \mathrm{g}$ FLAG-PTB, $2 \mu \mathrm{g}$ pUC 18, $2 \mu \mathrm{L}$ siRNA). Cells were expanded to $30-\mathrm{mm}$ plates after $4 \mathrm{~h}$. After an additional $48 \mathrm{~h}$, cells were harvested for Western blot and RNA analysis.

\section{Primer extension and RT-PCR}

Primer extension was carried out as previously described (Modafferi and Black 1997) using the same primer (DUPRT\#3), except that $20 \mu \mathrm{g}$ of RNA were used for primer extension. The amount of the product was quantified on Molecular Dynamics' Typhoon PhosphorImager using ImageQuant software.

RT-PCR was conducted as previously described (Hall et al. 2004) except that the $5^{\prime}$ primer was DUP-8 (5'-GACACCATGCA TGGTGCACCTG-3') and the $3^{\prime}$ primer was DUPRT\#3 (Modafferi and Black 1997). PCR was performed for 25 cycles and the amount of product was quantified as in the primer extensions.

\section{In vitro splicing}

T7 RNA polymerase reactions were carried out in the presence of cap analog and $\alpha-{ }^{32}$ P UTP as described (Chan and Black 1997). In vitro splicing was conducted in $25-\mu \mathrm{L}$ reactions using $\mathrm{HeLa}$ or WERI-1 nuclear extract as previously described (Chan and Black 1995).

\section{ACKNOWLEDGMENTS}

We thank the UCLA-DOE Biochemistry Instrumentation Facility for conducting the ultracentrifugation experiments and National Cell Culture Center (NCCC) for the HeLa cells. We thank Fred Allain and Stephen Curry for communicating unpublished results. We are grateful to Florian Oberstrass for assistance with the siRNA experiments, to Jiuyong Xie for the DUP4-1S plasmid, and to Guillaume Chanfreau, Fred Allain, and the members of the Black laboratory for helpful suggestions and critical comments on the manuscript. This work was supported by NIH Grant RO1GM48662 to D.L.B., who is an investigator of the Howard Hughes Medical Institute.

Received February 1, 2005; accepted February 18, 2005.

\section{REFERENCES}

Banerjee, H., Rahn, A., Davis, W., and Singh R. 2003. Sex lethal and U2 small nuclear ribonucleoprotein auxiliary factor (U2AF65) recognize polypyrimidine tracts using multiple modes of binding. RNA 9: 88-99.

Bevilacqua, P.C., George, C.X., Samuel, C.E., and Cech, T.R. 1998. Binding of the protein kinase PKR to RNAs with secondary structure defects: Role of the tandem A-G mismatch and noncontiguous helixes. Biochemistry 37: 6303-6316.

Black, D.L. 2003. Mechanisms of alternative pre-messenger RNA splicing. Annu. Rev. Biochem. 72: 291-336.

Black, D.L. and Grabowski, P.J. 2003. Alternative pre-mRNA splicing and neuronal function. Prog. Mol. Subcell. Biol. 31: 187-216.

Blanchette, M. and Chabot, B. 1997. A highly stable duplex structure sequesters the $5^{\prime}$ splice site region of hnRNP Al alternative exon 7B. RNA 3: 405-419.

. 1999. Modulation of exon skipping by high-affinity hnRNP A1-binding sites and by intron elements that repress splice site utilization. EMBO J. 18: 1939-1952.

Carstens, R.P., Wagner, E.J., and Garcia-Blanco, M.A. 2000. An intronic splicing silencer causes skipping of the IIIb exon of fibroblast growth factor receptor 2 through involvement of polypyrimidine tract binding protein. Mol. Cell. Biol. 20: 7388-7400.

Chan, R.C. and Black, D.L. 1995. Conserved intron elements repress splicing of a neuron-specific c-src exon in vitro. Mol. Cell. Biol. 15: 6377-6385. [Erratum (1997): Mol. Cell. Biol. 17: 2970.] 1997. The polypyrimidine tract binding protein binds upstream of neural cell-specific c-src exon N1 to repress the splicing of the intron downstream. Mol. Cell. Biol. 17: 4667-4676. 
Charlet, B.N., Logan, P., Singh, G., and Cooper, T.A. 2002. Dynamic antagonism between ETR-3 and PTB regulates cell type-specific alternative splicing. Mol. Cell 9: 649-658.

Chou, M.Y., Rooke, N., Turck, C.W., and Black, D.L. 1999. hnRNP H is a component of a splicing enhancer complex that activates a c-src alternative exon in neuronal cells. Mol. Cell. Biol. 19: 69-77.

Chou, M.Y., Underwood, J.G., Nikolic, J., Luu, M.H., and Black, D.L. 2000. Multisite RNA binding and release of polypyrimidine tract binding protein during the regulation of c-src neural-specific splicing. Mol. Cell 5: 949-957.

Cohn, E.J. and Edsall, J.T. 1943. Density and apparent specific volume of proteins. In Proteins, amino acids and peptides as ions and dipolar ions, pp. 370-381. Reinold, New York.

Conte, M.R., Grune, T., Ghuman, J., Kelly, G., Ladas, A., Matthews, S., and Curry, S. 2000. Structure of tandem RNA recognition motifs from polypyrimidine tract binding protein reveals novel features of the RRM fold. EMBO J. 19: 3132-3141.

Darnell, J.C., Jensen, K.B., Jin, P., Brown, V., Warren, S.T., and Darnell, R.B. 2001. Fragile X mental retardation protein targets $G$ quartet mRNAs important for neuronal function. Cell 107: 489499.

Del Gatto-Konczak, F., Olive, M., Gesnel, M.C., and Breathnach, R. 1999. hnRNP A1 recruited to an exon in vivo can function as an exon splicing silencer. Mol. Cell. Biol. 19: 251-260.

Dominski, Z. and Kole, R. 1991. Selection of splice sites in pre-mRNAs with short internal exons. Mol. Cell. Biol. 11: 6075-6083.

England, T.E., Bruce, A.G., and Uhlenbeck, O.C. 1980. Specific labeling of 3' termini of RNA with T4 RNA ligase. Methods Enzymol. 65: $65-74$.

Flanagan, M., Liang, H., and Norton, P.A. 2003. Alternative splicing of fibronectin mRNAs in chondrosarcoma cells: Role of far upstream intron sequences. J. Cell. Biochem. 90: 709-718.

Gooding, C., Roberts, G.C., Moreau, G., Nadal-Ginard, B., and Smith, C.W. 1994. Smooth muscle-specific switching of $\alpha$-tropomyosin mutually exclusive exon selection by specific inhibition of the strong default exon. EMBO J. 13: 3861-3872.

Gooding, C., Roberts, G.C., and Smith, C.W. 1998. Role of an inhibitory pyrimidine element and polypyrimidine tract binding protein in repression of a regulated $\alpha$-tropomyosin exon. RNA 4: 85-100.

Grachev, M.A., Kolocheva, T.I., Lukhtanov, E.A., and Mustaev, A.A. 1987. Studies on the functional topography of Escherichia coli RNA polymerase. Highly selective affinity labelling by analogues of initiating substrates. Eur. J. Biochem. 163: 113-121.

Grachev, M.A., Lukhtanov, E.A., Mustaev, A.A., Zaychikov, E.F., Abdukayumov, M.N., Rabinov, I.V., Richter, V.I., Skoblov, Y.S., and Chistyakov, P.G. 1989. Studies of the functional topography of Escherichia coli RNA polymerase. A method for localization of the sites of affinity labelling. Eur. J. Biochem. 180: 577-585.

Gromak, N., Matlin, A.J., Cooper, T.A., and Smith, C.W. 2003. Antagonistic regulation of $\alpha$-actinin alternative splicing by CELF proteins and polypyrimidine tract binding protein. RNA 9: 443-456.

Hall, M.P., Huang, S., and Black, D.L. 2004. Differentiation-induced colocalization of the KH-type splicing regulatory protein with polypyrimidine tract binding protein and the c-src pre-mRNA. Mol. Biol. Cell 15: 774-786.

Hutchison, S., LeBel, C., Blanchette, M., and Chabot, B. 2002. Distinct sets of adjacent heterogeneous nuclear ribonucleoprotein (hnRNP) A1/A2 binding sites control 5' splice site selection in the hnRNP A1 mRNA precursor. J. Biol. Chem. 277: 29745-29752.

Jellinek, D., Green, L.S., Bell, C., and Janjic, N. 1994. Inhibition of receptor binding by high-affinity RNA ligands to vascular endothelial growth factor. Biochemistry 33: 10450-10456.

Jin, W., Bruno, I.G., Xie, T.X., Sanger, L.J., and Cote, G.J. 2003. Polypyrimidine tract-binding protein down-regulates fibroblast growth factor receptor $1 \alpha$-exon inclusion. Cancer Res. 63: 61546157.

Kashima, T. and Manley, J.L. 2003. A negative element in SMN2 exon 7 inhibits splicing in spinal muscular atrophy. Nat. Genet. 34: 460463.
Laue, T.M. 2001. Biophysical studies by ultracentrifugation. Curr. Opin. Struct. Biol. 11: 579-583.

Laue, T.M., Shah, B.D., Ridgeway, T.M., and Pelletier, S.L. 1992. Computer-aided interpretation of analytical ultracentrifugation of analytical sedimentation data for proteins. In Analytical ultracentrifugation in biochemistry and polymer science, pp. 90-125. The Royal Society of Chemistry, Redwood Press limited, Melksham, Wiltshire, England.

Lin, C.H. and Patton, J.G. 1995. Regulation of alternative 3' splice site selection by constitutive splicing factors. RNA 1: 234-245.

Liu, H., Zhang, W., Reed, R.B., Liu, W., and Grabowski, P.J. 2002. Mutations in RRM4 uncouple the splicing repression and RNAbinding activities of polypyrimidine tract binding protein. RNA 8: $137-149$.

Markovtsov, V., Nikolic, J.M., Goldman, J.A., Turck, C.W., Chou, M.Y., and Black, D.L. 2000. Cooperative assembly of an hnRNP complex induced by a tissue-specific homolog of polypyrimidine tract binding protein [in process citation]. Mol. Cell. Biol. 20: 7463-7479.

Meisenheimer, K.M. and Koch, T.H. 1997. Photocross-linking of nucleic acids to associated proteins. Crit. Rev. Biochem. Mol. Biol. 32: 101-140.

Milligan, J.F., Groebe, D.R., Witherell, G.W., and Uhlenbeck, O.C. 1987. Oligoribonucleotide synthesis using T7 RNA polymerase and synthetic DNA templates. Nucleic Acids Res. 15: 8783-8798.

Modafferi, E.F. and Black, D.L. 1997. A complex intronic splicing enhancer from the c-src pre-mRNA activates inclusion of a heterologous exon. Mol. Cell. Biol. 17: 6537-6545.

Mulligan, G.J., Guo, W., Wormsley, S., and Helfman, D.M. 1992. Polypyrimidine tract binding protein interacts with sequences involved in alternative splicing of $\beta$-tropomyosin pre-mRNA. J. Biol. Chem. 267: 25480-25487.

Norton, P.A. 1994. Polypyrimidine tract sequences direct selection of alternative branch sites and influence protein binding. Nucleic Acids Res. 22: 3854-3860.

Oh, Y.L., Hahm, B., Kim, Y.K., Lee, H.K., Lee, J.W., Song, O., Tsukiyama-Kohara, K., Kohara, M., Nomoto, A., and Jang, S.K. 1998. Determination of functional domains in polypyrimidine-tractbinding protein. Biochem. J. 331: 169-175.

Pérez, I., Lin, C.H., McAfee, J.G., and Patton, J.G. 1997a. Mutation of PTB binding sites causes misregulation of alternative $3^{\prime}$ splice site selection in vivo. RNA 3: 764-778.

Pérez, I., McAfee, J.G., and Patton, J.G. 1997b. Multiple RRMs contribute to RNA binding specificity and affinity for polypyrimidine tract binding protein. Biochemistry 36: 11881-11890.

Polydorides, A.D., Okano, H.J., Yang, Y.Y., Stefani, G., and Darnell, R.B. 2000. A brain-enriched polypyrimidine tract-binding protein antagonizes the ability of Nova to regulate neuron-specific alternative splicing. Proc. Natl. Acad. Sci. 97: 6350-6355.

Shen, H., Kan, J.L., Ghigna, C., Biamonti, G., and Green, M.R. 2004. A single polypyrimidine tract binding protein (PTB) binding site mediates splicing inhibition at mouse IgM exons M1 and M2. RNA 10: 787-794.

Simpson, P.J., Monie, T.P., Szendroi, A., Davydova, N., Tyzack, J.K., Conte, M.R., Read, C.M., Cary, P.D., Svergun, D.I., Konarev, P.V., et al. 2004. Structure and RNA interactions of the N-terminal RRM domains of PTB. Structure (Camb.) 12: 1631-1643.

Singh, R., Valcarcel, J., and Green, M.R. 1995. Distinct binding specificities and functions of higher eukaryotic polypyrimidine tractbinding proteins. Science 268: 1173-1176.

Smith, C.W. and Valcarcel, J. 2000. Alternative pre-mRNA splicing: The logic of combinatorial control. Trends Biochem. Sci. 25: 381-388.

Southby, J., Gooding, C., and Smith, C.W.J. 1999. Polypyrimidine tract binding protein functions as a repressor to regulate alternative splicing of $\alpha$-actinin mutually exclusive exons. Mol. Cell. Biol. 19: 2699-2711.

Tange, T.O., Damgaard, C.K., Guth, S., Valcarcel, J., and Kjems, J. 2001. The hnRNP Al protein regulates HIV-1 tat splicing via a novel intron silencer element. EMBO J. 20: 5748-5758. 
Valcarcel, J. and Gebauer, F. 1997. Post-transcriptional regulation: The dawn of PTB. Curr. Biol. 7: R705-R708.

Varani, G. and Nagai, K. 1998. RNA recognition by RNP proteins during RNA processing. Annu. Rev. Biophys. Biomol. Struct. 27: 407-445.

Wagner, E.J. and Garcia-Blanco, M.A. 2001. Polypyrimidine tract binding protein antagonizes exon definition. Mol. Cell. Biol. 21: 3281-3288.

. 2002. RNAi-mediated PTB depletion leads to enhanced exon definition. Mol. Cell 10: 943-949.

Wollerton, M.C., Gooding, C., Robinson, F., Brown, E.C., Jackson, R.J., and Smith, C.W. 2001. Differential alternative splicing activity of isoforms of polypyrimidine tract binding protein (PTB). RNA 7: 819-832.
Yuan, X., Davydova, N., Conte, M.R., Curry, S., and Matthews, S. 2002. Chemical shift mapping of RNA interactions with the polypyrimidine tract binding protein. Nucleic Acids Res. 30: 456462.

Zahler, A.M., Damgaard, C.K., Kjems, J., and Caputi, M. 2004. SC35 and heterogeneous nuclear ribonucleoprotein A/B proteins bind to a juxtaposed exonic splicing enhancer/exonic splicing silencer element to regulate HIV-1 tat exon 2 splicing. J. Biol. Chem. 279: 10077-10084.

Zhu, J., Mayeda, A., and Krainer, A.R. 2001. Exon identity established through differential antagonism between exonic splicing silencerbound hnRNP Al and enhancer-bound SR proteins. Mol. Cell 8: $1351-1361$. 

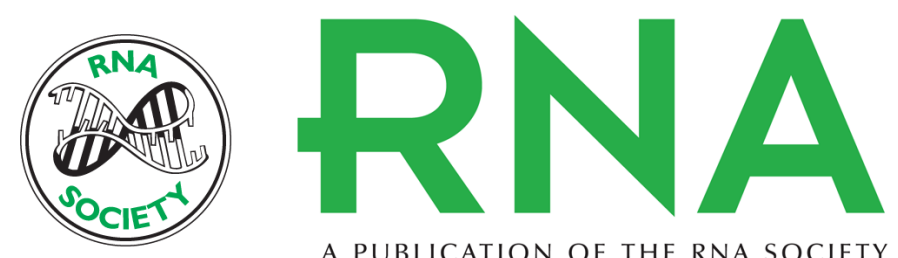

A PUBLICATION OF THE RNA SOCIETY

\title{
Exon repression by polypyrimidine tract binding protein
}

\author{
BATOUL AMIR-AHMADY, PAUL L. BOUTZ, VADIM MARKOVTSOV, et al.
}

RNA 2005 11: 699-716

References This article cites 53 articles, 29 of which can be accessed free at: http://rnajournal.cshlp.org/content/11/5/699.full.html\#ref-list-1

\section{License} Email Alerting
Service 